\title{
ANL-78-103
}

\section{ANALYSIS OF NONLINEAR FLUID STRUCTURE INTERACTION TRANSIENT IN FAST REACTORS}

by

C. Y. Wang

BASE TECHNOLOGY

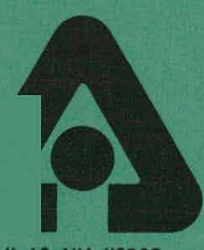

UOFC-AUA-USDOE

ARGONNE NATIONAL LABORATORY, ARGONNE, ILLINOIS

Operated for the U. S. DEPARTMENT OF ENERGY under Contract W-31-109-Eng-38 


\section{DISCLAIMER}

This report was prepared as an account of work sponsored by an agency of the United States Government. Neither the United States Government nor any agency Thereof, nor any of their employees, makes any warranty, express or implied, or assumes any legal liability or responsibility for the accuracy, completeness, or usefulness of any information, apparatus, product, or process disclosed, or represents that its use would not infringe privately owned rights. Reference herein to any specific commercial product, process, or service by trade name, trademark, manufacturer, or otherwise does not necessarily constitute or imply its endorsement, recommendation, or favoring by the United States Government or any agency thereof. The views and opinions of authors expressed herein do not necessarily state or reflect those of the United States Government or any agency thereof. 


\section{DISCLAIMER}

Portions of this document may be illegible in electronic image products. Images are produced from the best available original document. 
The facilities of Argonne National Laboratory are owned by the United States Government. Under the terms of a contract (W-31-109-Eng-38) between the U. S. Department of Energy, Argonne Universities Association and The University of Chicago, the University employs the staff and operates the Laboratory in accordance with policies and programs formulated, approved and reviewed by the Association.

\section{MEMBERS OF ARGONNE UNIVERSITIES ASSOCIATION}

The University of Arizona Carnegie-Mellon University Case Western Reserve University The University of Chicago University of Cincinnati Illinois Institute of Technology University of Illinois Indiana University Iowa State University The University of Iowa
Kansas State University The University of Kansas Loyola University Marquette University Michigan State University The University of Michigan University of Minnesota University of Missouri Northwestern University University of Notre Dame
The Ohio State University

Ohio University

The Pennsylvania State University Purdue University Saint Louis University Southern Illinois University The Universily of Texas at Austin Washington University Wayne State University The University of Wisconsin NOTICE

This report was prepared as an account of work sponsored by the United States Government. Neither the United States nor the United States Department of Energy, nor any of their employees, nor any of their contractors, subcontractors, or their employees, makes any warranty, express or implied, or assumes any legal liability or responsibility for the accuracy, completeness or usefulness of any information, apparatus, product or process disclosed, or represents that its use would not infringe privately-owned rights. Mention of commercial products, their manufacturers, or their suppliers in this publication does notimply or connote approval or disapproval of the product by Argonne National Laboratory or the U. S, Department of Energy.

Printed in the United States of America Available from

National Technical Information Service

U. S. Department of Commerce 5285 Port Royal Road

Springfield, Virginia 22161

Price: Printed Copy $\$ 5.25$; Microfiche $\$ 3.00$ 
ANL-78- 103

\section{ARGONNE NATIONAL LABORATORY 9700 South Cass Avenue \\ Argonne, Illinois. 60439} ANALYSIS OF NONLINEAR FLUID STRUCTURE
INTERACTION TRANSIENT IN FAST REACTORS

by

C. Y. Wang

Reactor Analy'sis and Safety Division

November 1978

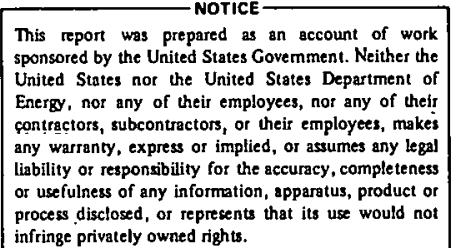

infringe privately owned rights. 


\section{THIS PAGE \\ WAS INTENTIONALLY \\ LEFT BLANK}




\section{TABLE OF CONTENTS}

$\underline{\text { Page }}$

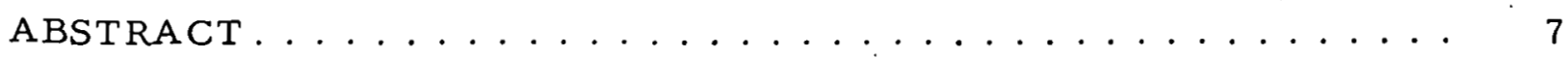

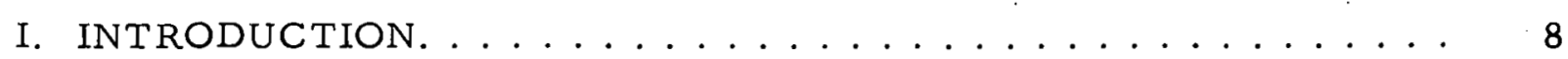

II. THE NUMERICAL TECHNIQUE ................... 10

A. Basic Hydrodynamics..................... 10

1. The Computing Region.................. 10

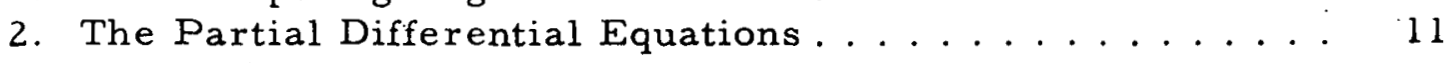

3. The Finite-difference Equations ............. 12

4. Particle Movement .................. 16

5. Rigid Obstacle and Rigid Thin Membrane ......... 17

B. Flexible Vessel and Arbitrarily Shaped Boundary . . . . . . . 20

1. Moving External Boundary and Cell Flag. . . . . . . . . 20

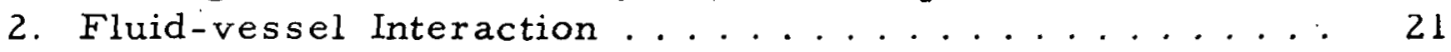

3. Velocity and Pressure Calculations near Boundary..... 23

C. Deformable Internal Structure . . . . . . . . . . . . . 24

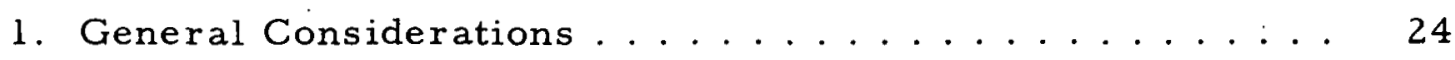

2. Source-term Modification near Structure........ 25

3. Interaction of Fluid with Internals and Perforated

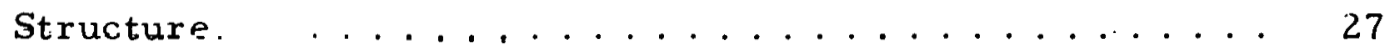

4. Calculation of Multivalued Field Variables ......... . . . . . . . .

5. Particle Movement near Corner ............. 31

D. Moving Cover and Coolant Spillage.............. 32

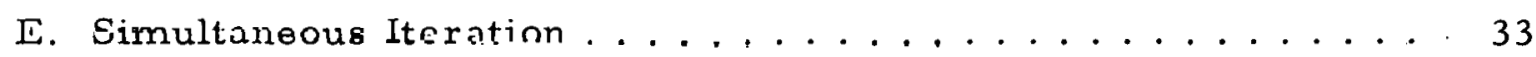

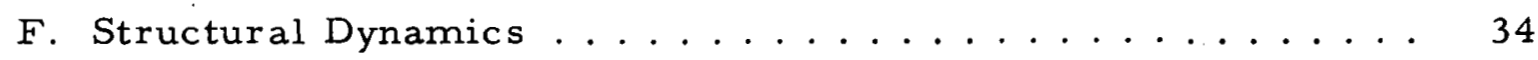

1. Finite-element Structural Program ........... 34

2. Finite-difference Shell Program ............ 36

G. Numerical Stability . . . . . . . . . . . . . 37

III. SAMPLE PROBLEMS . . . . . . . . . . . . . . . . . . . 39

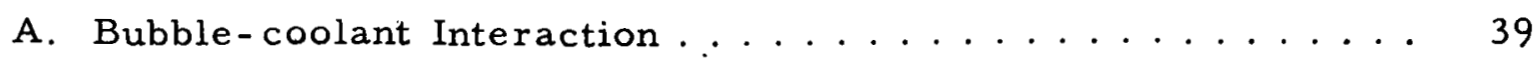

B. Wave Propagation in a Straight Pipe . . . . . . . . . . . 40

C. Response of the Primary Containment. . . . . . . . . . . 41 
TABLE OF CONTENTS

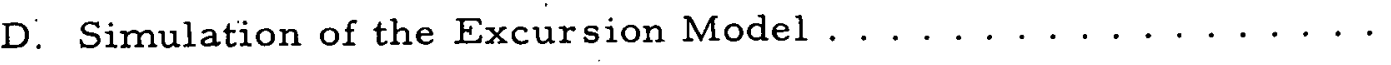
E. Responses of Structural Components. . 46

IV. CONCLUSIONS. ......................... 50

APPENDIX: Formulation of Explicit Boundary Conditions. . . . . . 52 ACKNOWLEDGMENTS . . . . . . . . . . . . . . . . . 56

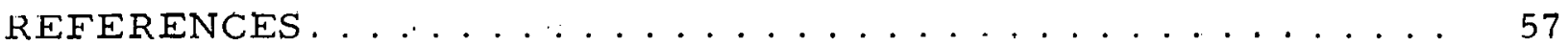




\section{LIST OF FIGURES}

No.

Title

Page

1. Configuration Showing Eulerian Computational Mesh and Lagrangian Structure Boundary. ............... 10

2. The Locations of the Cell Variables in a Eulerian Computational Cell. .................. 12

3. Linear Interpolation for $u_{k}$ and $v_{k}$ with Position of kth Particle as Shown ................... 17

4. Velocity Arrangement in the Vicinity of the Rigid Obstacle . . . 18

5. Velocity Arrangement in the Vicinity of a Rigid Thin Membrane . 19

6. Velocity Components of Marker Particle near Rigid Obstacle and Thin Membrane ................... 19

7. Configuration of a Moving External Boundary .......... 21

8. Different Types of Eulerian Cell Flags. . . . . . . . . . . 21

9. Calculations of Vessel Pressure and Boundary-cell Velocity . . 23

10. Example Illustrating the Need for the Multivalued Field

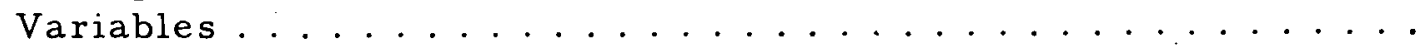

11. Velocities Needed for $R_{j+(1 / 2), j}$ Calculation near the Deformable Internal Structure

12. Velocities Need for $R_{i+(1 / 2), j}$ Calculation in the Internal Boundary Lell $(1, j) \ldots \ldots \ldots \ldots$

13. Irregular Cell $(k, 1)$ Containing Deformable Structure with Perforated Openings . . . . . . . . . . . . . .

14. Eulerian Finite-difference Mesh with Multivalued Field Variables Adjacent to the Ihick Internal Struclurei. . . . . . . .

15. Eulerian Finite-difference Mesh with Multivalued Field Variables Adjacent to the Thin Internal Structure. . . . . . . .

16. Particle Velocities near the Corner............... 32

1. R. Rasi-Eulerian Cell and Penetration Openings. . . . . . . . 32

18. Flow Chart Representing the Computational Procedure...... 35

19, Shell of Revolution and Free-body Diagram. . . . . . . . . 37

20. Bubble Motion and Coolant Configuration at Different Times . . . 39

21. Mathematical Model and Configuration of Elastic-Plastic Pipe Used in the ICECO Analysis . . . . . . . . . . . . . . . 


\section{LIST OF FIGURES}

No.

22. Calculated Pressure Histories at Locations A, B, and C......

23. Radial Deformations as a Function of Time at Locations $\mathrm{D} 1, \mathrm{D} 2$, and $\mathrm{D} 3 \ldots \ldots \ldots$

24. Initial Configuration of the Primary Containment Used in the Analysis . . . . . . . . . . . . . . . . 42

25. Reactor Configurations at Three Different Times . . . . . . . 43

26. Model Test Configuration for the Containment Studies . . . . . . . 43

27. Configurations of Thin-vessel Test. . . . . . . . . . . 44

28. Vessel Deformation at $z=36 \mathrm{~cm} \ldots \ldots 46$

29. Vessel Deformation at $z=4 \mathrm{~cm} \ldots \ldots \ldots$. . . . . . . .

30. Final Deformation of the Thin Vessel . . . . . . . . . . 47

31. The Mathematical Model Used for the Component-response Analysis. .......................... 47

32. Configurations of Primary Containment and Components at Three Different Times .................. 48

33. Calculated Axial Displacements as a Function of Time . . . . . 48

34. Calculated Radial Displacements as a Function of Time . . . . . 49

Al. Vessel with Almost Vertical Orientation for the Derivation of the Explicit Boundary Condition...........

A2. Vessel with Almost Horizontal Orientation for the Derivation of the Explicit Boundary Condition ...........

\section{TABLE}

No. Title

I. Source Characteristics for the Thin-vessel Model......... 
ANALYSIS OF NONLINEAR FLUID STRUCTURE

INTERACTION TRANSIENT IN FAST REACTORS

by

C. Y. Wang

\section{ABSTRACT}

A generalized Eulerian method is described for analyzing the fluid transients and the structural response in nuclear reactors under the postulated accident conditions. The phenomena to be considered are the wave propagation, slug impact, sodium spillage, bubble migration, and the fluid-structure interaction.

The implicit, iterative finite-difference scheme is employed in the numerical analysis together with implicit treatment of the density variation in the equation of state of the media. Many options are provided to model the complicated structural components in a typical reactor configuration, including the rigid obstacle, rigid thin membrane, arbitrarily shaped boundary, flexible moving vessel, deformable internals, perforated core-support structure, and the movable cover with penetrations.

The method uses Poisson equations to determine the hydrodynamic pressures in the fluid region as well as underneath the head, while utilizing the relaxation equations to compute the pressures adjacent to the vessel and internals. A generalized cuupling scheme is developed for troating the sliding-boundary conditions at the fluid-structure interfaces. This scheme enables the Eulerian hydrodynamic technique to be linked with any Lagrangian structural dynamics program.

In this report, the basic equations and numerical formulation are presented in detail. Sample calculations are given to illustrate the analysis. It is shown from the results that this implicit, iterative method is unconditionally stable and is especially suitable for problems involving large material distortions. 


\section{INTRODUCTION}

In the design of Liquid Metal Fast Breeder Reactor (LMFBR) it is necessary to assure that the containment system can withstand all the consequences during a Hypothetical Core Disruptive Accident (HDCA). The destructive phenomena to be considered are the wave propagation, slug impact, sodium spillage, and the expanding gas bubble. ${ }^{1}$ The primary containment is designed to sustain the pressure waves emanating from the reactor core. The secondary containment is to confine the radioactive materials from being released to the surrounding environs. To achieve this objective, an analysis of the structure response generated by the fluid-structure interaction is of primary importance.

Analysis of the coupled fluid-structure problem is a complex subject since it involves calculations of fluid transient, fluid-structure interaction, and the resulting structure response. For a structural component enclosing or submerged within a fluid, the motion of the structure depends on the pressure loading transmitted from the fluid region, whereas the motion of the fluid depends on the movement of the structure boundary. Thus fluid and structure are coupled together. In fast-reactor safety analysis the problem of fluidstructure interaction is further complicated by the facts that ( 1 ) the struclural components usually have both geometrical and material nonlinearities, (2) the fluid is almost inviscid and tends to slide along the interface, (3) geometrical discontinuities like sharp corners and irregularities may exist in the fluid region, and (4) large material distortion, such as bubble contraction and sodium spillage, may occur during an HCDA. Since there are numerous finiteelement structural-dynamics programs available for solving complicated structures with material nonlinearities, the trend of current research concentrates on the development of an effective method to treat the fluid transient and fluid-structure interaction.

In attempts to solve the coupled fluid-structure problem, substantial research effort has been devoted in the application of existing hydrodynamic techniques for performing the numerical analysis of the fluid-structure interaction. Among these techniques, the Lagrangian finite-difference methods ${ }^{2,3}$ have been widely used by many investigators. These methods provide great resolution at the early stage of excursion, but cannot handle large material distortion such as bubble contraction and sodium spillage. Also, it is difficult to treat the sliding-boundary condition at interfaces between fluids and reactor internals, as well as to handle the fluid motion at geometrical discontinuities, such as sharp corners and other irregularities.

On the other hand, the Eulerian hydrodynamic methods ${ }^{4,5}$ are excellent in treating distortions. However, these methods lack the capability to treat the time-dependent irregular cells created by the movement of the structure with respect to the fixed Eulerian coordinates. Thus, engineering applications have been limited by the requirement that the external boundary and internal structure must be placed on the Eulerian grid lines. 
To overcome the difficulties of both the Lagrangian and Eulerian methods, this report describes a generalized Eulerian method for analyzing the fluid-structure interaction in reactor containments and components. The emphasis is on the development of a generalized hydrodynamic scheme for treating the irregular cells and providing sliding capabilities at the interface, as well as analysis of the fluid motion at the geometrical discontinuities.

Thus, the developed scheme enables us to model reactor configurations realistically, using options such as the rigid obstacle, rigid thin membrane, curved vessel boundary, perforated core-support structure, and movable head with penetrations. It also enables the implicit continuous-fluid Eulerian (ICE) technique to be coupled with any Lagrangian structural dynamic program. Recently, the Eulerian hydrodynamic code $I C E C O^{6}$ has been successively linked together with both finite-difference and finite-element Lagrangian programs. The new version of the ICECO code, which has capabilities of investigating the structure response, is called ICECO-STR (or ICECO-II).

In the analysis, the Eulerian description is used in the hydrodynamic calculation while the Lagrangian representation is employed for the structure analysis. These two calculations are coupled together at the interface where the boundary conditions are satisfied. Thus, the ICECO-STR has essentially features similar to coupled Euler-Lagrangian programs such as the PISCES$2 \mathrm{DELK}^{7}$ and $C E L^{8}$ codes. The major difference is that the present technique uses implicit integration in the hydrodynamics, while the two techniques mentioned above employ an explicit integration scheme. As will be demonstrated later, the implicit scheme provides remarkably stable solutions. However, the explicit technique usually leads to numerical instabilities and needs to introduce artificial viscosities to eliminate the spurious oscillations.

In this report, the basic equations are given in Sect. II, together with the mathematical treatment of the rigid obstacle, rigid thin membrane, curved vessel boundary, deformable internals, etc. Sample problems are presented in Sect. III. 


\section{TIIE NUMERICAL TECHNIQUE}

A. Basic Hydrodynamics

1. The Computing Region

To facilitate the numerical calculations, the fluid regions are represented by the marker particles similar to the Marker and Cell (MAC)

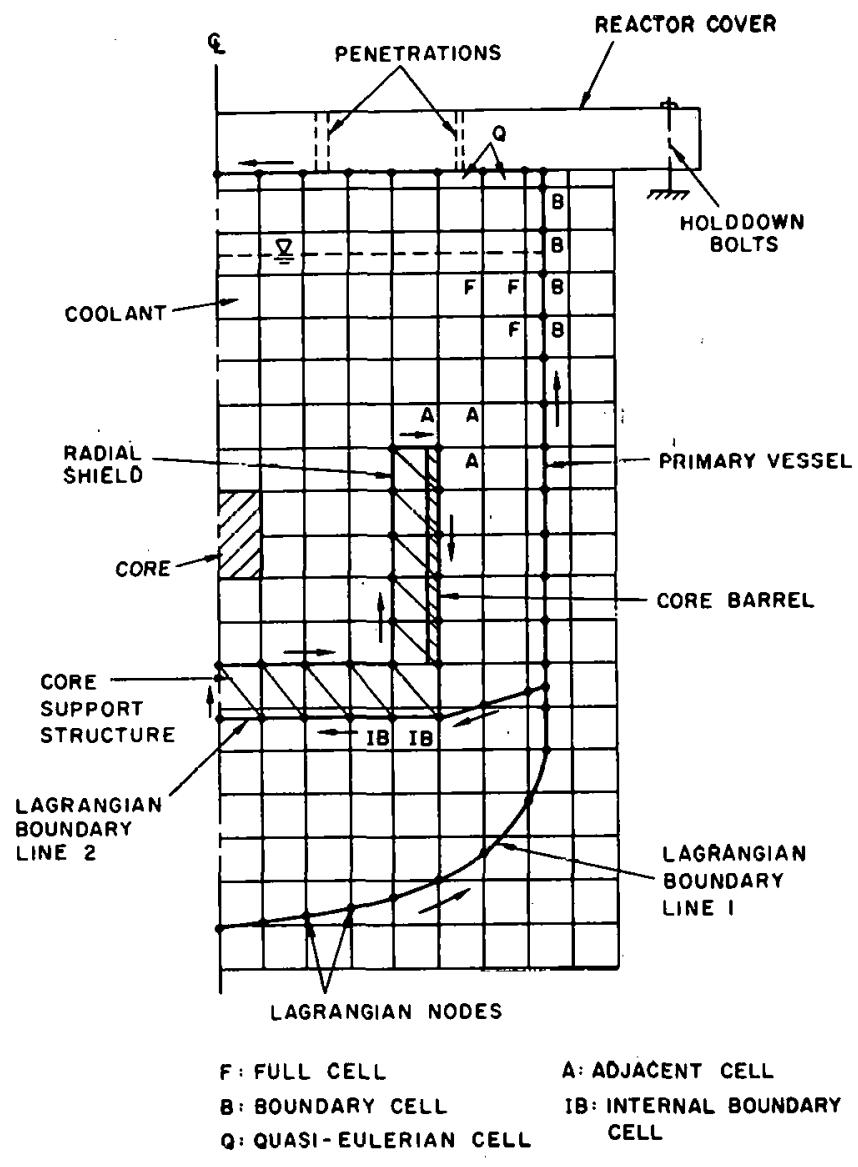

Fig. 1. Configuration Showing Eulerian Computational Mesh and Lagrangian Structure Boundary. ANL Neg. No. 900-77-191 Rev. 1. method. ${ }^{9}$ The structural component can be discretized into number of node points described by the Lagrangian coordinates as shown in Fig. 1. The boundaries of the structures thus can be denoted by one or more Lagrangian lines through ronnertions of exterior nodes of the structurod. Thooc moving Lagrangian lines intersecting the fixed Eulerian mesh will create numerous timedependent boundary cells which partially contain the fluid. In the computer program, a cellidentification scheme is developed so that different types of cells can be distinguished and the corresponding governing equations can be assigned. Here, a few important cells should be mentioned and their numerical treatments will be presented in the following sections:

$$
\text { (1) A full (F) cell contains }
$$

fluid only.

(2) A boundary (B) cell contains segment of vessel boundary.

(3) An internal boundary (IB) cell has a boundary segment of the internal structure which may have perforated openings.

(4) An adjacent (A) cell is full with fluid, but is located next to the internal boundary cell.

(5) A Quasi-Eulerian (Q) cell is underneath the reactor cover where sodium spillage may occur. 


\section{The Partial Differential Equatións}

The partial differential equations used in the method are the conservation equations of continuum mechanics. These equations are written in cylindrical coordinates with axial symmetry. For problems involving plane coordinates, the equations are modified by maintaining $r=1.0$ throughout. Only nonturbulent flow is considered, and no external energy source is as sumed to exist inside the flow region. Thus, the mass, momentum, and energy equations are:

$$
\begin{gathered}
\frac{\partial p}{\partial t}+\frac{1}{r} \frac{\partial \rho r u}{\partial r}+\frac{\partial \rho v}{\partial z}=0 \\
\frac{\partial \rho u}{\partial t}+\frac{1}{r} \frac{\partial \rho u^{2} r}{\partial r}+\frac{\partial \rho u v}{\partial z}=-\frac{\partial}{\partial r}(p+q)+\mu \frac{\partial}{\partial z}\left(\frac{\partial u}{\partial z}-\frac{\partial v}{\partial r}\right) \\
\frac{\partial \rho v}{\partial t}+\frac{1}{r} \frac{\partial \rho u v r}{\partial r}+\frac{\partial \rho v^{2}}{\partial z}=-\frac{\partial}{\partial z}(p+q)-\frac{\mu}{r} \frac{\partial}{\partial r}\left[r\left(\frac{\partial u}{\partial z}-\frac{\partial v}{\partial r}\right)\right] \\
\frac{\partial \rho E}{\partial t}+\frac{1}{r} \frac{\partial \rho u E r}{\partial r}+\frac{\partial \rho v E}{\partial z}=\frac{1}{r} \frac{\partial}{\partial r}\left\{r\left[-p u-\left(\frac{\lambda}{\lambda+2 \mu}\right) q u+\frac{\mu}{2} \frac{\partial}{\partial r}\left(2 u^{2}+v^{2}\right)+\mu v \frac{\partial u}{\partial z}\right]\right\}
\end{gathered}
$$

and

$$
+\frac{\partial}{\partial z}\left\{-p v-\left(\frac{\lambda}{\lambda+2 \mu}\right) q v+\frac{\mu}{2} \frac{\partial}{\partial z}\left(u^{2}+2 v^{2}\right)+\mu u \frac{\partial v}{\partial r}\right\}
$$

where

$$
q=-(\lambda+2 \mu)\left(\frac{1}{r} \frac{\partial u r}{\partial r}+\frac{\partial v}{\partial z}\right)
$$

$r$ and $z$ are the radial and axial coordinates, respectively, $u$ and $v$ are the corresponding radial and axial velocity components, $\rho$ is the density, $t$ is the time, $p$ is the pressure, $E$ is the specific total energy, and $\lambda$ and $\mu$ are, respectively, the first and second viscosity coefficients. These coefficients can be used as "artificial viscosities" to eliminate the shock discontinuity and numerical instability. The fluid is considered to be nonheat-conducting, and no external energy source is assumed to exist inside the fluid region. The pressure $p$ is related to $\rho$ and $I$ by an equation of state: 


$$
\rho=f(p, I) \text {, }
$$

in which

$$
I=E-\left[\left(u^{2}+v^{2}\right) / 2\right]
$$

is the specific internal energy.

\section{The Finite-difference Equations}

A Eulerian finite-difference mesh is shown in Fig. 2, which illustrates the centering of the physical variables relative to a typical cell. The center of the cell is labeled with the indices $i$ and $j$, which increase in the radial and axial directions, respectively. The velocities are defined at cell boundaries with $u$ at $i \pm(1 / 2)$ and $v$ at $j \pm(1 / 2)$. Other field variables such as $\rho, P, E$, and $I$ are all defined at the cell center.

$\operatorname{CELL}(i, j)$

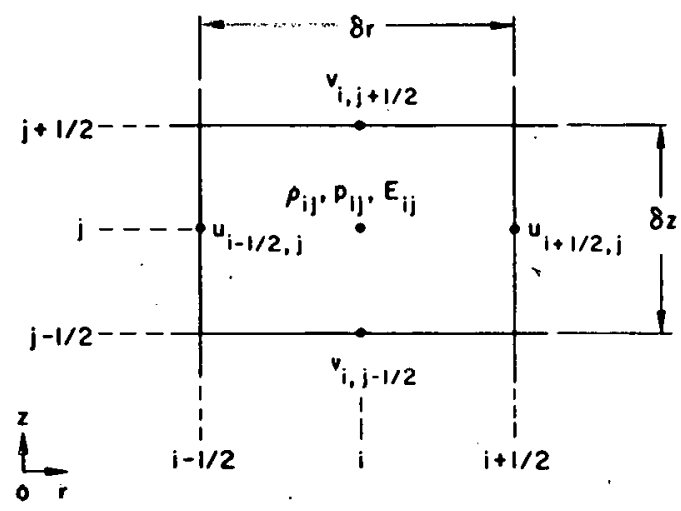

Fig. 2

The Locations of the Cell Variables in a Eulerian Computational Cell: ANL Neg. No. 900-78-140.

Thus, the viscous pressure $q$ expressed in the difference form

becomes

$$
\begin{aligned}
q_{i, j}= & -(\lambda+2 \mu)\left[\frac{1}{r_{i} \delta r}\left(r_{i+(1 / 2)} u_{i+(1 / 2), j}-r_{i-(1 / 2)} u_{i-(1 / 2), j}\right)\right. \\
& \left.+\frac{1}{\delta z}\left(v_{i, j+(1 / 2)}-v_{i, j-(1 / 2)}\right)\right],
\end{aligned}
$$

where $\delta \mathrm{r}$ is the dimension of a cell in the $\mathrm{r}$ direction.

To approximate the momentum equations in the finite-difference equations, the momentum-flux term can be expressed in either the ZIP or complete donor-cell form. Thus, using the ZIP difference scheme, we have, for example in the one-dimensional case, 


$$
\langle\rho u\rangle_{i}^{2}=\rho_{i} u_{i-(1 / 2)} u_{i+(1 / 2)} .
$$

In complete donor-cell expressions we obtain

$$
\langle\rho u\rangle_{i}^{2}=\left\{\begin{array}{lll}
\rho_{i} u_{i-(1 / 2)}^{2}, & \text { for } & \left(u_{i-(1 / 2)}+u_{i+(1 / 2)}\right)>0 \\
\rho_{i} u_{i+(1 / 2)}^{2} & \text { for } & \left(u_{i-(1 / 2)}+u_{i+(1 / 2)}\right)<0
\end{array}\right.
$$

Each of these two types of flux expressions has certain advantages. The ZIP form allows the conservation of momentum in the immediate vicinity of a rigid wall, and can eliminate certain nonlinear contributions to instability and diffusion-like truncation errors. ${ }^{10}$ Thus, as recommended by Harlow and Amsden in the ICE technique, the ZIP form is used in most occasions. How ever, the complete donor-cell expressions have an advantage in the case of violent fluid motion and can assist in giving an automatic mitigation of truncation-error effect. Such donor-cell form is therefore preferred in the sodium spillage analysis.

By use of the ZIP form the finite-difference expressions of the two momentum equations are:

$$
\begin{aligned}
\frac{(\rho u)_{i+(1 / 2), j}^{n+1}-(\rho u)_{i+(1 / 2), j}^{n}}{\delta t}= & \frac{\varphi}{\delta r}\left(p_{i, j}^{n+1}-p_{i+1, j}^{n+1}\right) \\
& +\frac{1 \varphi}{\delta r}\left(p_{i, j}^{n 1}-p_{i+1, j}^{11}\right)+R_{i+(1 / 2), j}
\end{aligned}
$$

and

$$
\begin{aligned}
\frac{(\rho v)_{i, j+(1 / 2)}^{n+1}-(\rho v)_{i, j+(1 / 2)}^{11}}{\delta t} & =\frac{\varphi}{\delta z}\left(p_{i, j}^{n+1}-p_{i, j+1}^{n+1}\right) \\
& +\frac{1-\varphi}{\delta z}\left(p_{i, j}^{n}-p_{i, j+1}^{n}\right)+S_{i, j+(1 / 2)}
\end{aligned}
$$

where

$$
\begin{aligned}
R_{i+(1 / 2), j} \equiv & \frac{1}{r_{i+(1 / 2)} \delta_{r}}\left[u_{i+(1 / 2), j}\left(\rho_{i, j} r_{i} u_{i-(1 / 2), j}-\rho_{i+1} r_{i+1} u_{i+(3 / 2), j}\right]+\frac{1}{\delta z}\left[(\rho u v)_{\left.i+(1 / 2), j-(1 / 2)-(\rho u v)_{i+(1 / 2), j+(1 / 2)}\right]}\right.\right. \\
& +\frac{1}{\delta r}\left(q_{i, j}-q_{i+1, j}\right)+g_{r} \rho_{i+(1 / 2), j}+\frac{\mu}{\delta_{z}}\left[\frac{u_{i+(1 / 2), j+1}-u_{i+(1 / 2), j}}{\delta_{z}}-\frac{v_{i+1, j+(1 / 2)}-v_{i, j+(1 / 2)}}{\delta_{r}}\right. \\
& \left.-\frac{u_{i+(1 / 2), j}-u_{i+(1 / 2), j-1}}{\delta_{z}}+\frac{v_{i+1, j-(1 / 2)}-v_{i, j-(1 / 2)}}{\delta r}\right]
\end{aligned}
$$


and

$$
\begin{aligned}
S_{i, j+(1 / 2) \equiv} & \frac{1}{r_{i} \delta r}\left[(\rho u v r)_{i-(1 / 2), j+(1 / 2)}-(\rho u v r)_{i+(1 / 2), j+(1 / 2)}\right] \\
& +\frac{1}{\delta z}\left[v_{i, j+(1 / 2)}\left(\rho_{i, j} v_{i, j-(1 / 2)}-\rho_{i, j+1} v_{i, j+(3 / 2)}\right]\right. \\
& +\frac{1}{\delta z}\left(q_{i, j}-q_{i, j+1}\right)+g_{z} \rho_{i, j+(1 / 2)} \\
& -\frac{\mu}{r_{i} \delta r}\left[r_{i+(1 / 2)}\left(\frac{u_{i+(1 / 2), j+1}-u_{i+(1 / 2), j}}{\delta z}-\frac{v_{i+1, j+(1 / 2)}-v_{i, j+(1 / 2)}}{\delta r}\right)\right. \\
& \left.-r_{i-(1 / L)}\left(\frac{u_{i-(1 / 2), j+1}-u_{i-(1 / 2), j}}{\delta z}=\frac{v_{i, j+(1 / 2)}-v_{i-1, j+(1 / 2)}}{\delta r}\right)\right] .
\end{aligned}
$$

In the above equations, the superscripts $n+1$ and $n$ denote the $(n+1)-$ th and nth time cycles. Variables lacking the time index are evaluated at the nth time cycle. $R$ and $S$ are the source terms of the momentum equations that contains the nth cycle values of nonlinear convective flux and viscous dissipation terms. Also, a weighting constant $\varphi$ appearing in the pressure gradients of Eqs. 9 and 10 is used in the numerical treatment, as suggested in the ICE technique. This constant $\varphi$, with a magnitude between 0.0 and 1.0 , represents the relative level of time centering of the pressure-gradient term. For $\varphi=1.0$, that term is expressed at the advanced time and the technique is purely implicit. For $\varphi=0.5$, the pressure gradient term is time-centered. This feature is used to eliminate certain truncation errors.

The equation of state can be put in the finite-difference form

$$
p_{i, j}^{n+1} \equiv p_{i, j}^{n}+c_{i, j}^{n}\left(p_{i, j}^{n+1}-p_{i, j}^{n}\right)
$$

where

$$
c_{i, j}^{n} \equiv\left(\frac{\partial p}{\partial p}\right)_{i, j}^{n}
$$

is related to the speed of sound.

Physically, Eq. 13 implies that the unknown advanced-time pressure depends implicitly on the density variation, but can remain purely explicit for the internal energy, as in the conventional explicit techniques. 
written as ${ }^{6}$.

For a condensed material such as sodium or water, $c_{i, j}^{n}$ can be

$$
c_{i, j}^{n}=\left[a_{0}^{2}\left(1+\frac{p^{n} \eta}{a_{0}^{2} \rho_{0}}\right) \frac{\rho_{0}}{\rho}\right]_{i, j},
$$

where $a_{0}$ and $\rho_{0}$ are the sound speed and density at standard condition, respectively. The constant $\eta$ is the isentropic exponent (or the pressure derivative of the bulk modulus).

Similar to the development of momentum equations, the mass equation can also be expressed in the time-centered form by introducing a weighting constant $\theta(0.0<\theta \geq 1.0)$ :

$$
\frac{\rho_{i, j}^{n+1}-\rho_{i, j}^{n}}{\delta t}=\theta D_{i, j}^{n+1}+(1-\theta) D_{i, j}^{n},
$$

where

$$
\begin{aligned}
D_{i, j}^{n+1}= & \frac{1}{r_{i} \delta r}\left[(\rho u)_{i-(1 / 2), j}^{n+1} r_{i-(1 / 2)}-(\rho u)_{i \cdot 1(1 / 2), j}^{n+1} r_{i+(1 / 2)}\right] \\
& +\frac{1}{\delta z}\left[(\rho v)_{i, j-(1 / 2)}^{n+1}-(\rho v)_{i, j+(1 / 2)}^{n+1}\right]
\end{aligned}
$$

represents the convection of mass flux of cell $(i, j)$ at the advanced-time cycle, and $D_{i, j}^{n}$ has exactly the same form as $D_{i, j}^{n+1}$ except that all terms are evaluated at the nth cycle.

Ellminatling the advanced-time quantitico $\rho_{i, j}^{n+1},(\rho u)_{i \pm(1 / 2), j}^{n+1}$, and $(\rho v)_{i, j \pm(1 / 2)}^{n+1}$ in Eq. 15 by means of Eqs. 9,10 , and 13, we obtain a Poisson equation which has the form

$$
\begin{aligned}
p_{i, j}^{n+1} & {\left[\frac{1}{c_{i, j}^{n}}+2 \theta \varphi \delta t^{2}\left(\frac{1}{\delta r^{2}}+\frac{1}{\delta z^{2}}\right)\right]=G_{i, j} } \\
& +\theta \varphi \delta t^{2}\left(\frac{r_{i-(1 / 2)} p_{i-1, j}^{n+1}+r_{i-(1 / 2)} p_{i+1, j}^{n+1}}{r_{i} \delta r^{2}}+\frac{p_{i, j-1}^{n+1}+p_{i, j+1}^{n+1}}{\delta z^{2}}\right),
\end{aligned}
$$


where

$$
G_{i, j}=G\left(R_{i \pm(i / 2), j}, S_{i, j \pm(1 / 2)}, u, v, p, \rho, c^{-1}, \ldots\right)
$$

is the source term of the pressure equation. It is a function of momentum source terms $R_{i \pm(1 / 2), j}$ and $S_{i, j \pm(1 / 2)}$ as well as $n$ th-cycle velocities, densities, pressure, and sound speed. This source term must be modified in the region near the structure.

Note that Eq. 16 is the governing difference equation for the advanced-time pressure in a cell completely filled with the fluid. In other words, this equation is applied for a full cell (F) shown in Fig. 1. It consists of five unknowns and is solved by the iteration technique.

In the ileralion process, a much improved formula is used by replasing $\left(n_{1-1, j}^{1+1}\right)^{h}$ and $\left(p_{i, j-1}^{n ! 1}\right)^{h}$ with the latest iterates $\left(p_{i=1, j}^{1+1}\right)^{h+1}$ and $\left(p_{i, j-1}^{i n ! 1}\right)^{h+1}$ while sweeping the direction of increasing $i$ and $j$. For a purely implicit scheme (i.e., $\theta=\varphi=1$ ), this yields

$$
\begin{aligned}
& \left(p_{i, j}^{n+1}\right)^{h+1}\left[\frac{1}{c_{i, j}^{n}}+2 \delta t^{2}\left(\frac{1}{\delta r^{2}}+\frac{1}{\delta z^{2}}\right)\right]=G_{i, j} \\
& +\delta t^{2}\left[\frac{r_{i-(1 / 2)}\left(p_{i-1, j}^{n+1}\right)^{h+1}+r_{i+(1 / 2)}\left(p_{i+1, j}^{n+1}\right)^{h}}{r_{i} \delta r^{2}}+\frac{\left(p_{i, j-1}^{n+1}\right)^{h+1}+\left(p_{i, j+1}^{n+1}\right)^{h}}{\delta z^{2}}\right]
\end{aligned}
$$

where $h$ and $h+1$ denote the previous and latest iterations, respectively.

If the fluid is bounded by the rigid walls and the wall boundaries coincide with the Eulerian grid.lines, Eq. 17 is sufficient to determine the advanced-time pressure field. After new pressures have been calculated in all the Eulerian cells, the new densities can be found from Eq. 13. Next, the new values of velocities can be computed from Eqs. 9 and 10.

To check the numerical accuracy, one can proceed to find the new energies for every cell, using the finite-difference approximation to Eqs. 4 and 6 given in Refs. 4 and 6.

\section{Particle Movement}

After solving for the advanced-velocity field and other field variables, a new configuration of the flow field is generated by moving the marker particles to their new positions: 


$$
r_{k}^{n+1}=r_{k}^{n}+u_{k} \delta t ; \quad z_{k}^{n+1}=z_{k}^{n}+v_{k} \delta t
$$

where $u_{k}$ and $v_{k}$ denote the velocity components for the kth particle. The values of $u_{k}$ and $v_{k}$ are obtained by averaging from the $u$ and $v$ fields, respectively. For example, if particle $k$ is located within the cell where $u_{1}$, $u_{2}, u_{3}$, and $u_{4}$ are defined at the nearby locations (see Fig. 3 ), $u_{k}$ can be calculated by the area-weighting method:

$$
u_{k}=\frac{A_{1} u_{1}+A_{2} u_{2}+A_{3} u_{3}+A_{4} u_{4}}{\delta r \delta z}
$$

similarly, $v_{k}$ is calculated by

$$
v_{k}=\frac{B_{1} v_{1}+B_{2} v_{2}+B_{3} v_{3}+B_{4} v_{4}}{\delta r \delta z}
$$
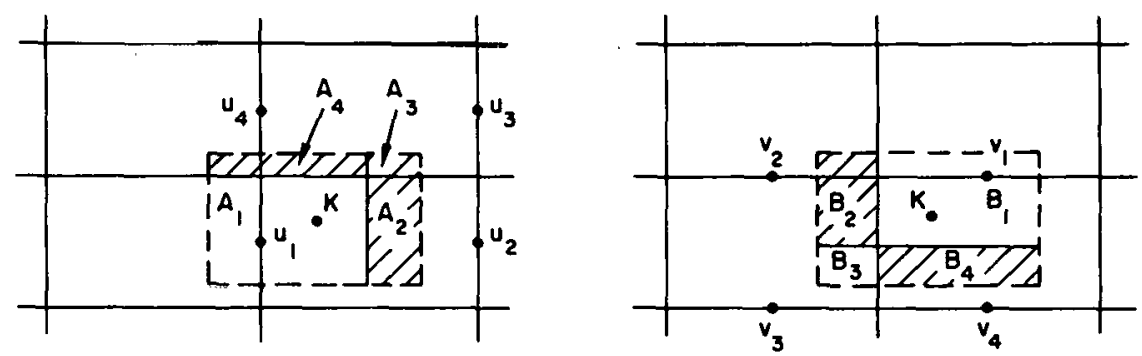

Fig. 3. Linear Interpolation for $\mathrm{u}_{\mathrm{k}}$ and $\mathrm{v}_{\mathrm{k}}$ with Position of kth Particle as Shown. ANL Neg. No. 900-78-913.

5. Rigid Obstacle and Rigid Thin Membrane

In the basic hydrodynamic technique rigid obstacles can be introduced in the computing region to model relatively thick structures such as the radial shield and the core-support structure. The restriction is that each obstacle must occupy one full Eulerian cell with its tour boundarles localed on the cell edges. Likewise, a rigid thin membrane, whether it is a shell or a plate, can also be used to simulate a thin structure like the core barrel. But the thin membrane must also be placed on the cell boundary with its dimension exactly equal to the width of the Eulerian cell. These two options could be very useful in analyzing the flow-blockage phenomena in other LMFBR components. In general, by modeling the internals as rigid materials the analysis would give a large impact on the vessel head and large vessel deformation at the upper containment wall; hence, the results are conservative. Conservatism is essential in the design of the head compartment.

Flow around the corners of obstacles presents numerous problems that must be considered consistently throughout the numerical analysis, as mentioned in the $\mathrm{MAC}^{9}$ method. First, when applying the Poisson equation to a full cell (F) adjacent to an obstacle cell, the pressure in the obstacle cell is 
not uniquely defined, but depends upon which full cell is being considered: During each iteration sweep, when applying the boundary conditions for cell (i,j) (see Fig. 4) the boundary pressure $P_{i+1, j}$ is different from that in the case of cell $(i+1, j+1)$. This causes no problem but must be kept in mind during the pressure iteration.

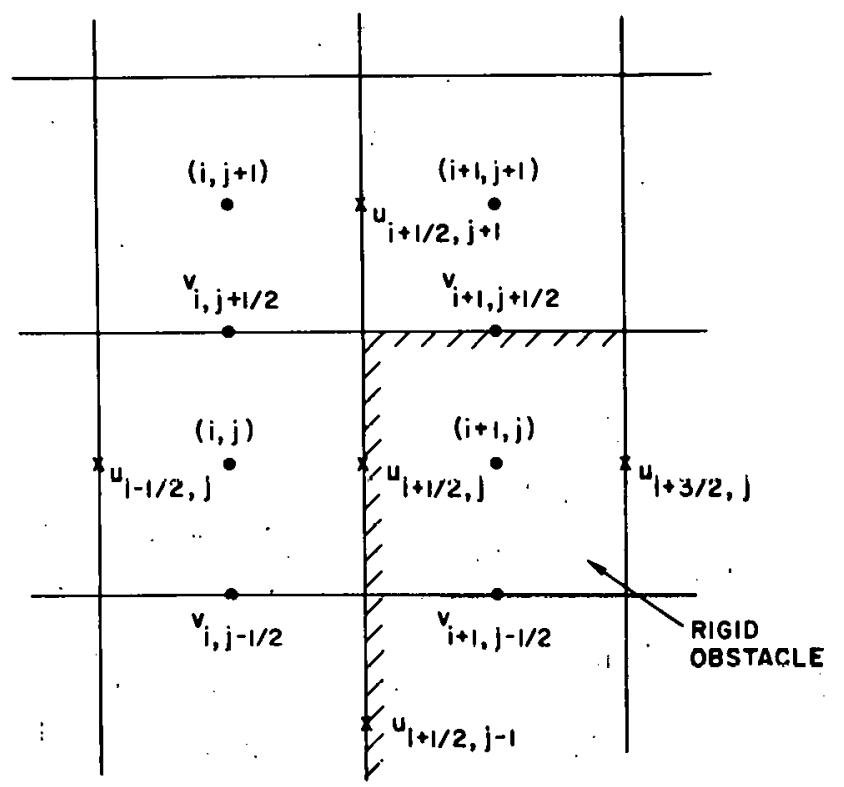

Fig. 4

Velocity Arrangement in the Vicinity of the Rigid Obstacle. A.NI, Neg. No. $900-78-931$.

Second, consideration must be given in calculating source terms $R_{i+(1 / 2), j}, S_{i, j+(1 / 2)}$, and $G_{i, j}$, since these source terms involve the velocities and densities in the neighboring obstacle cell. For the case shown in Fig. 4; $u_{i+(1 / 2), j}$ must be set equal to zero all the time. However, in making $u_{i+(1 / 2), j}$ equal to zero, which means if we actually calculate this velocity component from the radial momentum equation, we would indeed get zero. Therefore, a careful examination of the equation shows that in order to have zero radial velocity for cell $(i, j)$ the source term $R_{i+(1 / 2), j}$ must be set equal to zero. For a general fluid with nonzero viscosities the vanishing of $R_{i+(1 / 2), j}$ suggests that

$$
\begin{aligned}
\tilde{u}_{i+(1 / 2), j+1} & =0 ; \\
\tilde{v}_{i+1, j+(1 / 2)} & =v_{i, j+(1 / 2)} \\
\tilde{v}_{i+1, j-(1 / 2)} & =v_{i, j-(1 / 2)} \\
\tilde{u}_{i+(3 / 2), j} & =\frac{r_{i+1}(r u)_{i-(1 / 2), j}}{r_{i} r_{i+(3 / 2)}}
\end{aligned}
$$

In the above equations, the tilde quantities are the dummy values which are different from those computed by the conservation equations. 
Cells diagonal to a corner or next to a rigid thin membrane also need special treatment. In calculating $R_{i+(1 / 2), j+1}$ for cell $(i, j+1)$ shown in Figs. 4 and 5 , the stored value of $u_{i+(1 / 2), j}$ (zero) should not be used, but according to the inviscid boundary condition this velocity is set in such a way that

$$
u_{i+(1 / 2), j}=u_{i+(1 / 2), j+1}
$$

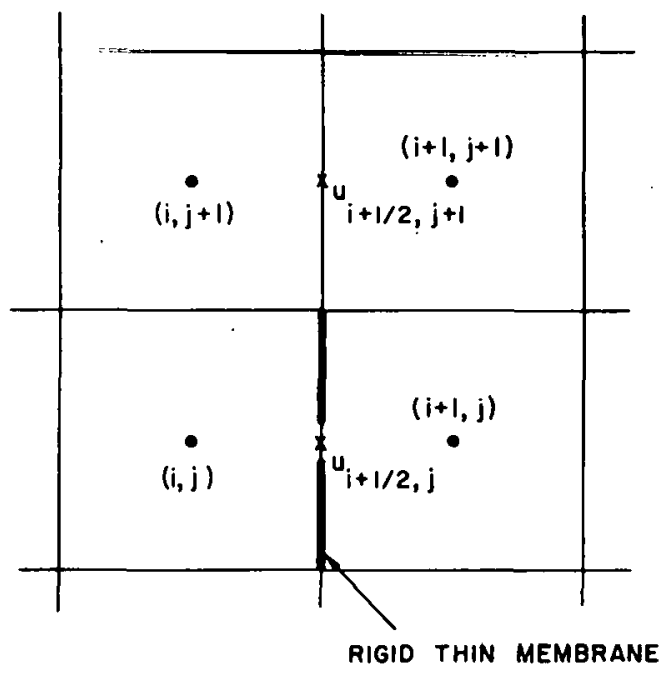

Fig. 5

Velocity Arrangement in the Vicinity of a Rigid Thin Membrane. ANL Neg. No. $900-78-912$.

Third, considerations also need to be given for the movement of a particle near rigid obstacle or thin membrane. Again, let us consider the calculation of the radial velocity component for the two cases shown in Fig. 6. According to the inviecid boundary conditinn, a particle below Line A must be moved with a radial velocity which assumes that the wall extends upward (i.e., $u_{1}=0$ ). On the other hand, a particle above Line $A$ must be moved in the radial direction as if the obstacle or thin membrane did not exist (i.e., $u_{3}=u_{1}$ ). Similar considerations can be applied to the axial particle-velocity cunpulalivin and to other oricntatione of obstasle or thin memhrane.

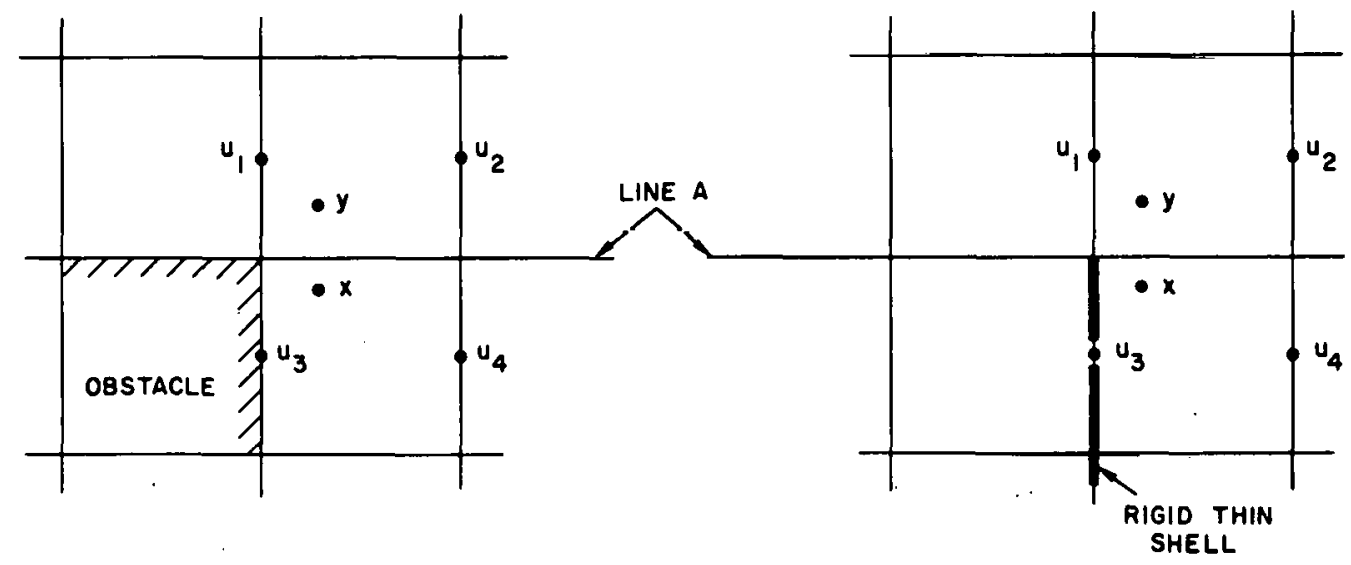

(a) obstacle

(b) THIN BOUNDARY SHELL

Fig. 6. Velnniry Commnents of Marker Particle near Rigid Obstacle and Thin Membrane. ANL Neg. No, 900-78-916. 
B. Flexible Vessel and Arbitrarily Shaped Boundary

1. Moving External Boundary and Cell Flag

As mentioned before, the Poisson equation is applicable only to a cell completely filled with the fluid. If the cell contains a boundary of the solid structure, the governing equation derived must satisfy the boundary condition at the fluid-structure interface. Since in each full cell the advancedtime pressure is the prime variable, it is advantageous to derive the equation for the boundary cell in terms of the advanced-time pressure so that all the equations can be solved together.

The scheme for treating the flexible containment vessel is similar to that used by Viecelli ${ }^{11,12}$ in the calculation of incompressible flows bounded by moving walls. In the case of inviscid boundary conditions the motion of an interface between the coolant and the arbitrarily shaped boundary (deformable containment vessel or curved rigid wall) is equivalent to that of a free surface with an applied pressure distribution. Given any interfacial shape or motion, one can produce that shape or motion with some unique pressure distribution applied to a free surface. Since the ICE technique and MAC method already have a technique for treating free surface, it is only necessary to find a way of relating the required pressure distribution to the motion and shape of the boundary.

A moving wall can be specified by a locus of node points described by the Lagrangian coordinates. These nodes are normally placed along the Eulerian grid lines as shown in Fig. 7a. The vessel boundary is therefore defined by a polygonal Lagrangian line, which is made up of straight line segments connecting the node points. A moving polygonal line intersecting the fixed Eulerian mesh will create numerous time-dependent irregular cells. Our approach is to match the boundary condition at the midpoint of each segment.

To simplify the analysis, we as sume that (1) the vessel boundary is fairly smooth, and that there are no situations in which the boundary wanders in and out of a single cell, creating irregularity, and (2) each boundary cell contains one and only one midpoint of the vessel segment, and thus avoids overdetermination of the pressure field. Having decomposed the boundary into a set of straight-line segments, each associated with a unique Eulerian cell, one can specify the position of each segment by a unit vector normal to the boundary with base positioned at the midpoint of the segment. Fig. $7 \mathrm{~b}$ shows the convention used in the analysis with the normal pointing into the coolant and to the left as one advances from the $i$-th to $(i+1)$-th boundary point. Since the boundary may be moving, it is also necessary to calculate a boundary velocity vector at the midpoint of each segment. This can be done simply by linear interpolation from the velocities obtained at the associated two node points through the structural dynamics calculation. 


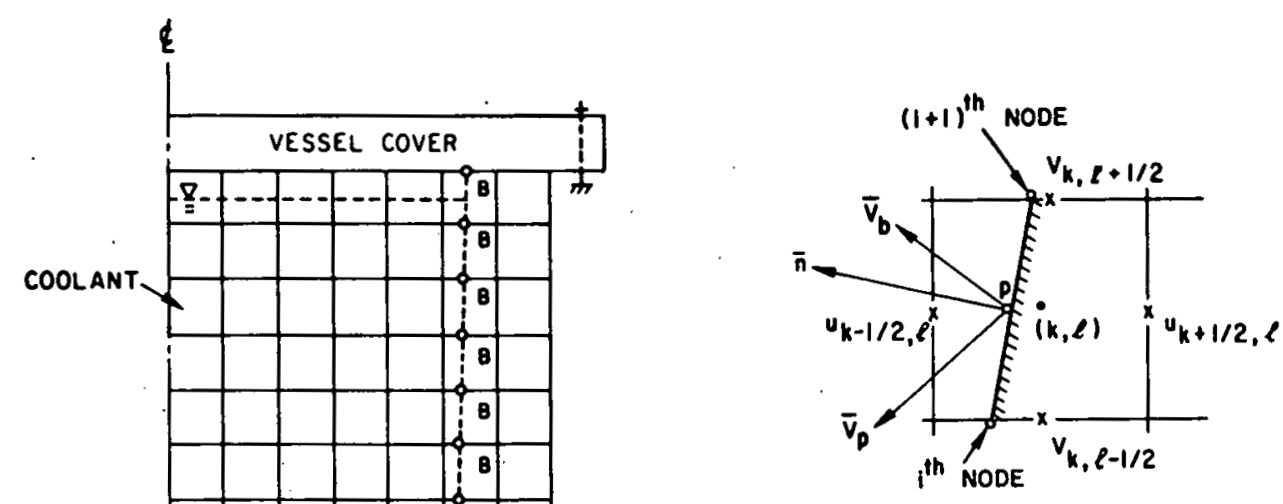

(b) BOUNDARY CELL $(k, l)$

COR

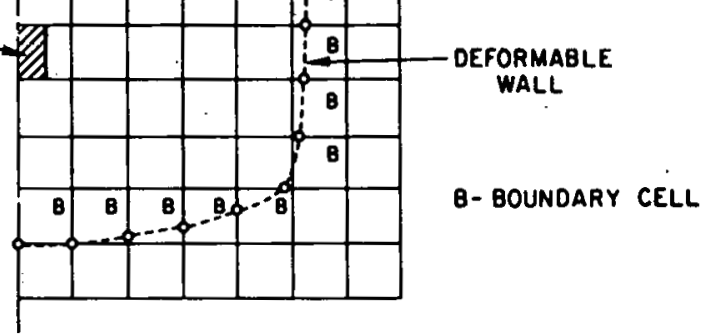

(a) CONFIGURATION

Fig. 7. Configuration of a Moving External Boundary.

ANL Neg. No. 900-5304 Rev. 1.
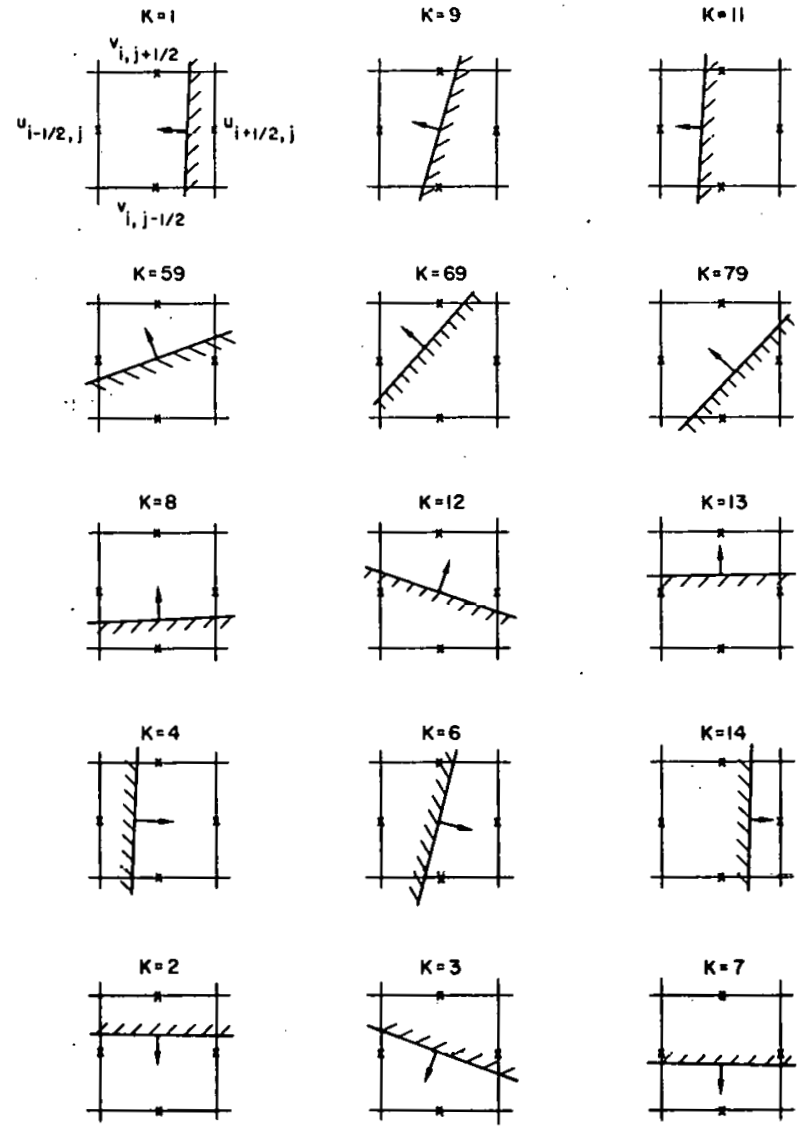

Fig. 8. Different Types of Eulerian Cell Flags. ANL Neg. No. 900-78-914.
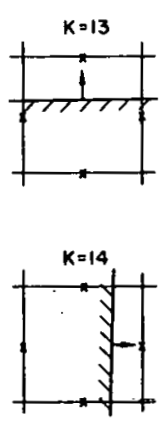

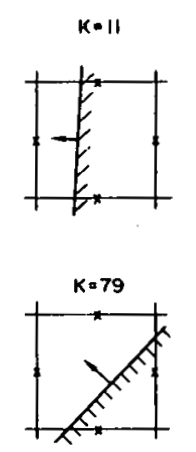

\section{Fluid-Vessel Interaction}

The viscous effect is neglected at the fluid-vessel inter face. The method treats the moving vessel in such a way that the fluid slides along the wall, but in the direction normal to the wall boundary, the fluid and the vessel wall being forced to move 
together. Thus, for each ccll that contains the moving boundary, the inviscid boundary condition yields

$$
\left(\bar{v}_{p}^{n+1}-\bar{v}_{b}\right) \cdot \bar{n}=0
$$

In this equation $v_{\mathrm{p}}^{\mathrm{n}+\mathrm{i}}$ is the velocity vector of a virtual particle located at the midpoint of the structure segment and can be computed by an area-weighting formula; $\bar{n}$ is the unit normal vector pointing into the fluid region; $\bar{v}_{b}$ is the velocity vector of the structure segment obtained from the Lagrangian structural-mechanics calculation; at the present time, $\bar{v}_{b}$ is evaluated at the previous time step, which is one cycle behind the particle velocity calculation. As can be seen from the later comparison between the analytical and experimental results, the approach used here provides very good results. Of course, the evaluation of $\ddot{v}_{h}$ at the advanced-time cycle is also feasible. However, this would bring $\bar{v}_{b}$ in the iteration process, which is very time-consuming and will be done only if justified by the future need.

A convenient procedure to solve Eq. 21 in the boundary cell is to express that equation in terms of the advanced-pressure field; then Eqs. 21 and $17 \mathrm{c}$ an be solved together. One way of doing this, according to Viecelli, ${ }^{12}$ is by introducing the relaxation parameter $\Delta \tau$ into the iteration process. Thus, denoting by $h$ and $h+1$ the previous and latest iteration, respectively, the advanced-pressure field is

$$
\left(p_{k, l}^{n+1}\right)^{h+1}=\left(p_{k, l}^{n+1}\right)^{h}-\left(\frac{\Delta \tau}{\delta}\right)\left\{\left[\left(\bar{v}_{p}^{n+1}\right)^{h}-\bar{v}_{b}\right] \cdot \bar{n}\right\}_{k, l}
$$

in which $\delta=\min (\delta \mathrm{r}, \delta \mathrm{z})$ and $\Delta \tau \leq \rho_{k, \ell} \delta^{2} / 2 \delta \mathrm{t}$.

In Eq. 22 the subscripts $k$ and $\ell$ refer to thc boundary cell $(k, l)$ having the vessel segment; $\left(v_{p}^{n+1}\right)_{k, l}^{h}$ is a new iterate that must be recomputed each time the pressures and velocities are adjusted. Note that by a continued iteration process, Eq. 22 is just the asymptotic solution of Eq. 21 . Also, during the pressure iteration one can see that if the fluid attempts to cross the boundary, the pressure in the boundary cell will be increased, forcing fluid to flow away from the boundary. On the other hand, if the fluid tends to separate from the boundary, the pressure will decrease until the fluid flows tangent to the boundary.

A real advantage of the implicit simultaneous iteration of Eq. 22 and the regular Poisson equation is that it gives a simple automatic way of including complicated boundary conditions. Thus, Eq. 22 is the principal formula used at the fluid-vessel interface and has been used in all the sample problems concerning the response of the containment vessel. Of course, one could iterate the advanced-time pressure field only by using the Poisson equation without computing the new densities and velocities as required by the relaxation equation. However, to do this, as discussed in Appendix $A$, one 
would have to derive explicit boundary conditions such that the flow would move tangential to the boundary. Although this can be done, it appears to be a formidable task to accomplish with generality because there are so many cases depending on the shape and orientation of the boundary.

\section{Velocity and Pressure Calculations near Boundary}

At each cycle of calculation, the hydrodynamic analysis supplies the structural-dynamic analysis with the hydrodynamic pressure, which is used to calculate the vessel response. In return, the structural-dynamic analysis feeds back the position and velocity of the structural member to the hydrodynamic analysis. Since in the fictitious boundary cell the hydrodynamic pressure must satisfy the interfacial boundary condition and could vary drastically from cycle to cycle, the fluctuating pressure sometimes will lead to unstable structural-dynamic analysis. Thus the pressure in the boundary cell should not be used for calculating the structural response. Instead, the pressure in the fluid cell immediately adjacent to the boundary cell will be considered as the pressure acting on the structural segment. Based on this approach, good results are obtained when comparisons of analytical and experimental solutions are made.

In the generalized method, the pressure transmitted to the structural member is easily determined if the vessel segments are oriented nearly vertical or horizontal. However, for the inclined vessel segment, the applied pressure can be interpolated either from the radial or axial direction, depending on which direction has the shortest distance from the cell center to the vessel segment. For the vessel segment shown in Fig. 9, the pressure applied to the structure is

$$
p_{g}=\left\{\begin{array}{l}
p_{i, j+1} \text { if } d_{1}<d_{2} \\
p_{i-1, j} \text { if } d_{1}>d_{2}
\end{array}\right.
$$

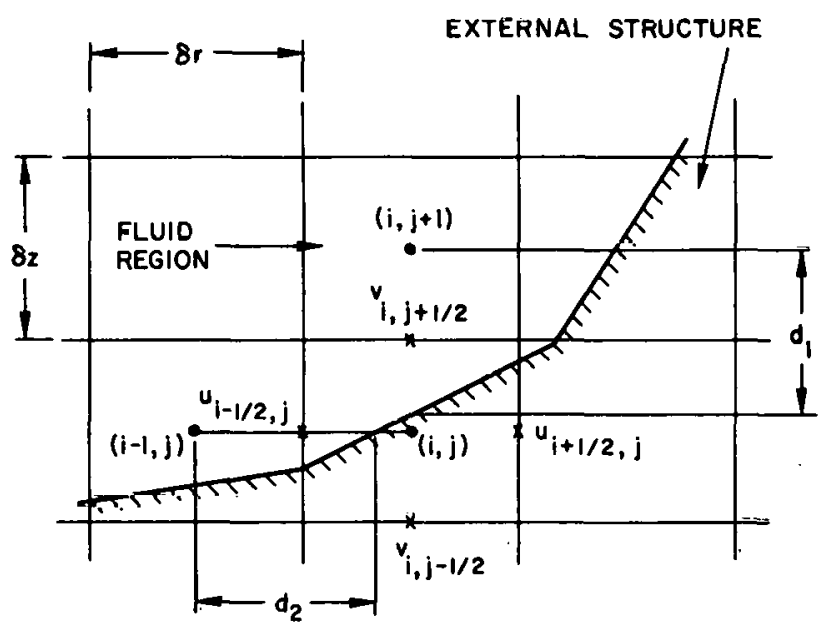

Fig. 9

Calculations of Vessel Pressure and Boundarycell Velocity. ANL Neg. No. 900-78-929. 
Velocities at exterior sides of the boundary cells and other exterior points are necessary in computing $\left(\bar{v}_{\mathrm{p}}^{n+1}\right)^{\text {h }}$ given in Eq. 22 and must be recomputed during each iteration sweep. These velocity components are determined in the same way as those on the open sides of free surface cells in the MAC method except for neglect of the effect of compressibility. The reason for the incompressibility assumption is also because a drastic change of the pressure in the fictitious cell could cause a significant change in density, which, in turn, will slow down the iteration process. Thus, for the case shown in Fig. 9, the velocity components on the exterior sides are:

$$
v_{i, j-(1 / 2)}=v_{i, j+(1 / 2)}
$$

and

$$
u_{i+(1 / 3), j}=\frac{u_{i-(1 / 2) \cdot j} j_{i-(1 / 2)}}{r_{1+(1 / 2)}}
$$

C. Deformable Internal Structure

\section{General Considerations}

Analysis of the fluid-structure interaction involving the reactor internals is very complicated due to the fact that the internal components may create discontinuities of fluid motion across the solid material, and that perforated structure and components with sharp corners may be present in the computing region. To analyze this problem rigorously a generalized coupling scheme is developed which includes the following considerations: (1) creating multivalued dummy variables near the structure, (2) generating a cell flag to indicate the relative position of the fluid with respect to the structure, (3) modifying the source terms in the momentum equations, (4) treating the structure components which may possess perforated openings, (5) calculating the multivalued field variables for different structures, and (6) moving particles near the sharp corner or irregularity. Here, we briefly discuss the first two items and leave others in the subsequent sections.

First, multivalued dummy field variables must be introduced in the vicinity of the structure, which is not necessary for the case of a moving external wall. This is because in the case of a moving external boundary, fluid is located only at one side of the structure. Thus, the field variable at the exterior side of the boundary cell can be extrapolated from the interior (fluid) side and has a single value throughout each cycle of calculation. However, this is not the case for the internal structure, which may have more than one side contacting the fluid. Here, the fluid variable defined at one location can be either computed from the conservation equation or extrapolated from different fluid sides, depending on which portion of the structure is being 
considered. For instance, let us consider just one radial velocity component $u_{1}$ near a structure submerged in the fluid shown in Fig. 10 . In cell $(i, j)$ the fluid

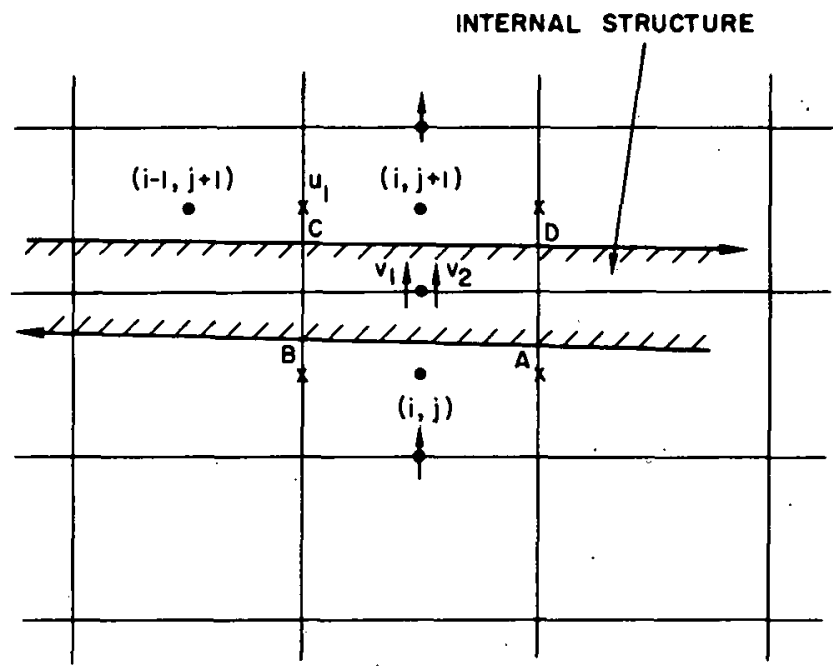

Fig. 10. Example Illustrating the Need for the Multivalued Field Variables. ANL Neg. No. 900-78-928. is located at the bottom of the structure, and the particle velocity. vector $\left(V_{p}\right)_{i, j}$, according to the areaweighting formula, is a function of unknown $u_{1}$. This unknown velocity component is extrapolated from the bottom side of the structure as if the structure occupied the entire region above $A B$. Likewise, in cell $(i, j+1)$ the particle velocity vector $\left(V_{p}\right)_{i, j+1}$ is also a function of $u_{1}$. But this time $u_{1}$ is directly computed from the momentum equation applied to cell $(i-1, j+1)$. Obviously, this radial velocity has two distinct values, and the value used for cell $(i, j+1)$ will override the first value utilized for cell $(i, j)$. This velocity will also be used at other occasions, such as for the source-term calculation and the particle movement. The two different values should be saved. One way to remedy this situation is to introduce multivalued variables; the variable obtained from the conservation equation is designed in the normal manner, whereas the value extrapolated from the fluid side is denoted by a superscript which indicates the relative position of the fluid with respect to the structure.

Second, having introduced multivalued variables, à criteriun

- (or a flag) must be established to indicate the position of the fluid relative to the structure. Here, we refer to Fig. 8 and as sume that the fluid is at the left when the flag KF equals to $1,9,11,59,69$, or 79 ; the fluid is at top when $\mathrm{KF}$ equals to 8,12 , or 13 ; at right when $\mathrm{KF}$ equals to 4,6 , or 14 ; and at bottom when $\mathrm{KF}$ equals to 2,3 , or 7 .

Since we have introduced multivalued field variables near the structure, source terms of the momentum equations and the Poisson equation in the fluid cell adjacent to the structure and in the cell containing the boundary need certain modification. Thus, we should identify both adjacent and boundary cells before doing the modification. The boundary cell is already identified by the boundary-cell flag. The adjacent cell also can be easily identified simply by searching its eight surrounding cells.

\section{Source-term Modification near Structure}

If a cell is an adjacent (A) cell, special consideration must be given in calculating its source terms $R_{i+(1 / 2),} G_{i, j-1(1 / 2)}$, and $G_{i, j}$ because 
these source terms involve the velocities in the neighboring boundary cells, which cannot be computed directly from the momentum equations. To illustrate the necessary modification of the source term, we consider some velocity treatment of $R_{i+(1 / 2), j}$ for an adjacent cell $(i, j)$ shown in Fig. 11 . For conve nience, we neglect the viscous-diffusion and body-force terms, and express $R_{i+(1 / 2), j}$ explicitly as

$$
\begin{aligned}
R_{i+(1 / 2), j}= & \frac{1}{r_{i}+(1 / 2)^{\delta r}}\left[u_{i}+(1 / 2), j\left(\rho_{i, j} r_{i} u_{i}-(1 / 2), j-\rho_{i+1, j} r_{i+(3 / 2), j}\right)\right] \\
& +\frac{1}{\delta z}\left[(\rho u v)_{i+(1 / 2), j-(1 / 2)}-(\rho u v)_{i+(1 / 2), j+(1 / 2)}\right] .
\end{aligned}
$$

With an ex $(x)$ indicating the $u$ velocities and a dot $(\cdot)$ the $v$ velocities needed for computing $\mathrm{R}_{\mathrm{i}}\left(\mathrm{l}_{1 / 2), \mathrm{j}}\right.$ as shown in $\mathrm{Fig}$. 11 , one can see that the re are three velocities $\left(v_{i+1, j}^{\ell}, v_{1+1, j, 1}^{\ell}\right.$, and $u \ell_{i \mid 3 / 2, j}^{\ell}$, denoted by two dots and one ex) located, at positions occupied by the structure. Since cell $(i+1, j)$ is a partial cell these three velocities cannot be obtained from the hydrodynamic equations, but are extrapolated from the fluid region at the left-hand side in accordance with the sliding-boundary condition at the interface. If the superscript $l$ is used to denote the position of cell $(i, j)$ relative to the structure, the unknown axial velocities are calculated from

$$
v_{i+1, j}^{l}=v_{i, j} ; \quad v_{i+1, j-1}^{l}=v_{i, j-1}
$$

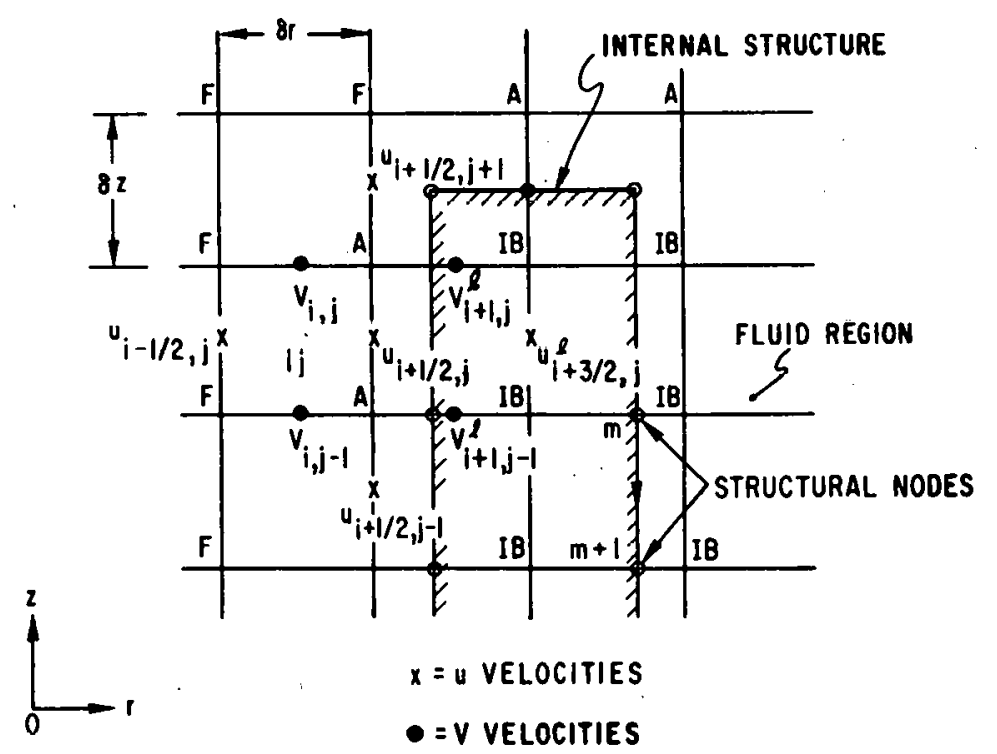

Fig. 11

Velocities Needed for $R_{i+(1 / 2), j}$ Calculation near the Deformable Internal Structure. ANL Neg. No. 900-77-505 Rev. 3.

The unknown radial velocity $u_{i}^{l}+\left(3 / 2^{\prime}\right), j$ can be calculated from the mass equation by neglecting the variation of density and has the form 


$$
\begin{aligned}
u_{i+3 / 2, j}= & \frac{r_{i+1} \delta r}{r_{i+3 / 2}}\left\{\frac{1}{r_{i+1} \delta r} u_{i+(1 / 2), j} r_{i+(1 / 2)}\right. \\
& \left.+\frac{1}{\delta z}\left[v_{i+1, j-(1 / 2)}-v_{i+1, j+(1 / 2)}\right]\right\} .
\end{aligned}
$$

Similar considerations must be given to the calculations of $S_{i, j+(1 / 2)}$ and of other orientations of structure components relative to the cell $(i, j)$.

If a cell is an internal boundary (IB) cell, attention also should be

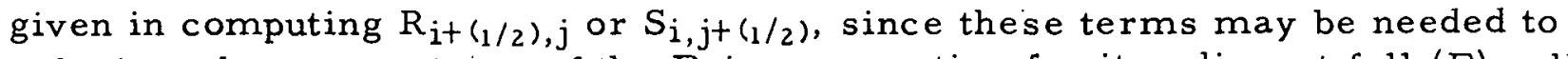
calculate the source term of the Poisson equation for its adjacent full (F) cell. One typical example is shown in Fig. 12, where $R_{i+(1 / 2), j}$ is utilized for computing $G_{i+1}, j$. Again, in this case the four unknown velocities $u_{i-(1 / 2), j}^{r}, v_{i, j}^{r}+(1 / 2)$, $v_{i, j-(1 / 2)}^{r}$, and $u_{i+(1 / 2), j-1}^{t}$ (represented by two dots and two exes) can be obtained from an inviscid boundary condition and the mass-conservation equation, similar to the scheme used in an adjacent (A) cell.

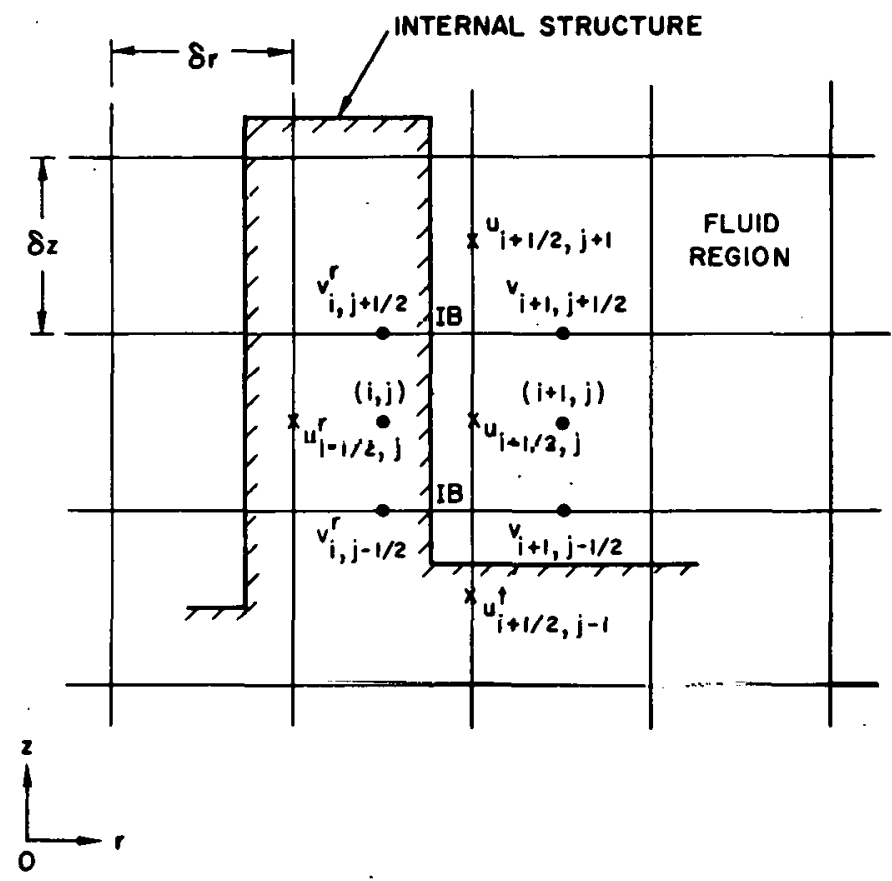

Fig. 12

Velocities Needed for $R_{i+(1 / 2), j}$ Calculation in the Internal Boundary Celi $(i, j)$. ANL Neg. No. 900-78-930.

3. Interaction of Fluid with Internals and Perforated Structure

Although the internal solid structure can be modeled by rigid obstacles and thin membranes as mentioned in Sect. III.A.5, the solutions obtained usually overestimate the pressure loadings and vessel deformations near the upper containment vessel. Another difficulty is to model the core-supportstructure openings correctly. If we assume the opening is a full cell, the 
results would overestimate the pressure loadings in the reactor lower plenum. Also, the limitation on the locations of rigid obstacle and thin membrane is found to be too restrictive. Therefore, a general method for treating deformable internals as well as perforated structure must be developed to analyze the response of the primary containment systems realistically.

In order to accommodate the deformable internal and the perforated structures, we provide a scheme which still uses the relaxation equation to obtain the pressure adjacent to the structure but modifies that equation to account for the sodium flow through the openings. The basic idea is to homogenize the perforated structure member so that the total mass flux through the openings is uniformly distributed throughout the entire member. In other words, for those members containing openings, such as $A B$ and $C D$ in Fig. 13. we allow fluid penetration and separation at the boundaries. To simplify the analysis, we further propose that:

(a) Fluids inside the coolant passage move one dimensionally.

(b) Sodium flows perpendicularly to the boundary at the entrance

or exit.

(c) The density variation inside the coolant passage is negligible, so that the amount of mass flowing into the passage is equal to the mass flowing out of the passage.

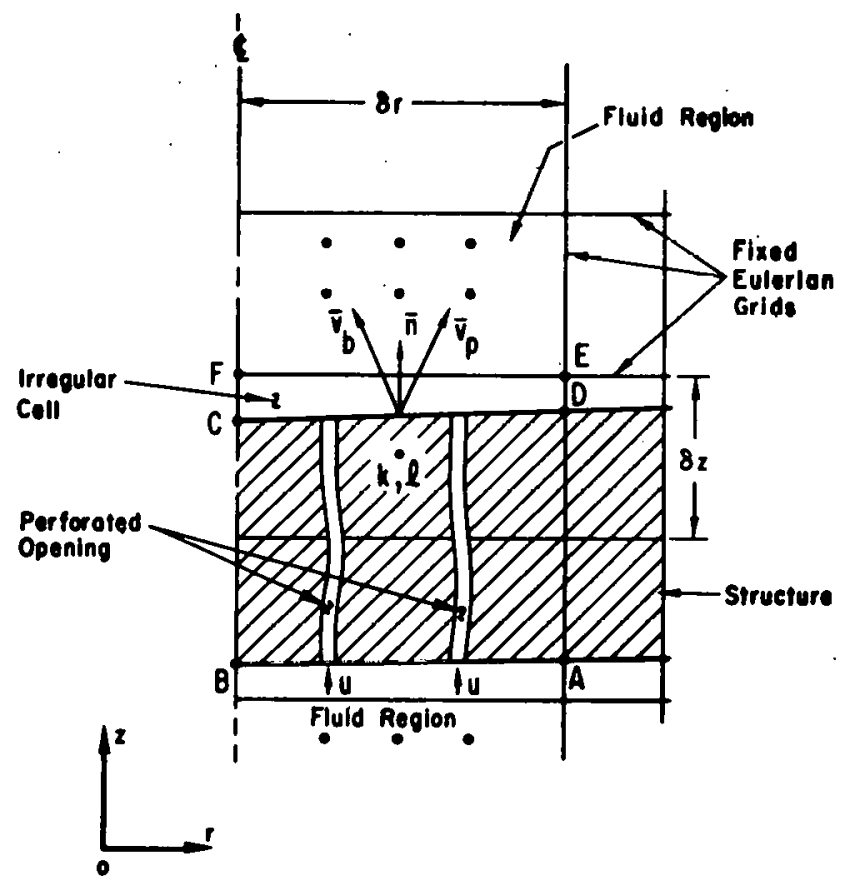

Fig. 13

Irregular Cell $(k, 1)$ Containing Deformable Structure with Perforated Openings. ANL Neg. No. 900-77-241A. 
Thus, for a structure with or without coolant passage openings, the inviscid condition implies that the mass flux across the boundary must be equal to the total mass passing through the openings:

$$
p\left(\overline{\mathrm{v}}_{\mathrm{p}}^{\mathrm{n}+1}-\overline{\mathrm{v}}_{\mathrm{b}}\right) \cdot \overline{\mathrm{n}}=\theta
$$

where $\theta$ is the amount of mass flux through the openings.

Note that with $\theta$ equal to zero, the above equation is just the nonpenetration condition applied at the boundary of the deformable structure. Also note that a superscript $t$ indicating the position of the fluid relative to the structure has been omitted.

Similar to the development of the relaxation equation at the coolantvessel interface, the $h+1$ iteration value of the advanced-pressure.field is

$$
\mathrm{p}_{\mathrm{k}, \ell}^{\mathrm{h}+1}=\mathrm{p}_{\mathrm{k}, \ell}^{\mathrm{h}}-\frac{\Delta \mathrm{T}}{\delta}\left\{\rho\left(\overline{\mathrm{v}}_{\mathrm{p}}^{\mathrm{h}}-\overline{\mathrm{v}}_{\mathrm{b}}\right) \cdot \overline{\mathbf{n}}-\theta\right\}_{\mathrm{k}, \ell} .
$$

For the perforated structure (see Fig. 13), the amount of mass flux, $\theta_{k, l}$, through the structure openings can be calculated from

$$
\theta_{k, l}=(\rho \psi u)_{k, l}
$$

where $\psi$ is the perforation ratio, defined as the ratio of the flow area to the total area covered by the structural member. The change of the fluid velocity $\mathrm{u}$ in the coolant-passage ojpening 3 can bo calculated from

$$
\frac{\mathrm{du}}{\mathrm{dt}}=\frac{\mathrm{p}_{\mathrm{k}, \ell}-\mathrm{p}_{\mathrm{k}, \ell-1}-\Delta \mathrm{p}}{\rho L}
$$

where $p_{k, l-1}$ and $p_{k, l}$ are the pressures on both sides of the structure, $L$ is the mean'length of the coolant passage associated with the corresponding structural member, and $\Delta p$ is the pressure loss due to friction, which in certain circumstances can be directly related to $|u|^{1.75}$ (see Ref. 13).

\section{Calculation of Multivalued Field Variables}

Since fluids have different motions on both sides of the internal structure, the field variables in a cell containing structure are assumed to have different values. In particular, the velocity field is used to compute the source terms in the momentum and Poisson's equations, and also to move the marker particles. It is also utilized in handling the fluid motion at the geometrical discontinuities. Thus, for a structure submerged in the fluid, as shown in Fig. 14, the two sets of velocity field: $u_{1}^{l}, v_{1}^{l}, v_{2}^{l}$ and $u_{1}^{r}, v_{1}^{r}, v_{2}^{r}$, are 
calculated from the inviscid boundary conditions and the mass equations corresponding to the fluid located at the left-hand and right-hand sides, respectively. Upon neglecting the density variations, these velocities can be expressed as

$$
\begin{aligned}
& v_{1}^{l}=v_{i, j+(1 / 2)} \\
& v_{2}^{l}=v_{i, j-(1 / 2)} \\
& u_{1}^{l}=\frac{r_{i} \delta r}{r_{i+(1 / 2)}}\left\{\frac{1}{r_{i} \delta r} u_{i-(1 / 2), j} r_{i-(1 / 2)}+\frac{1}{\delta z}\left[v_{i, j-(1 / 2)}-v_{i, j+(1 / 2)}\right]\right\},
\end{aligned}
$$

and

$$
\begin{aligned}
& v_{1}^{r}=v_{i+2, j+(1 / 2)} \\
& v_{2}^{r}=v_{i+2, j-(1 / 2)} \\
& u_{1}^{r}=\frac{r_{i+1} \delta r}{r_{i+(1 / 2)}}\left\{\frac{1}{r_{i+1} \delta r} u_{i+3 / 2, j} r_{i+3 / 2}-\frac{1}{\delta z}\left[v_{2}^{r}-v_{1}^{r}\right]\right\}
\end{aligned}
$$

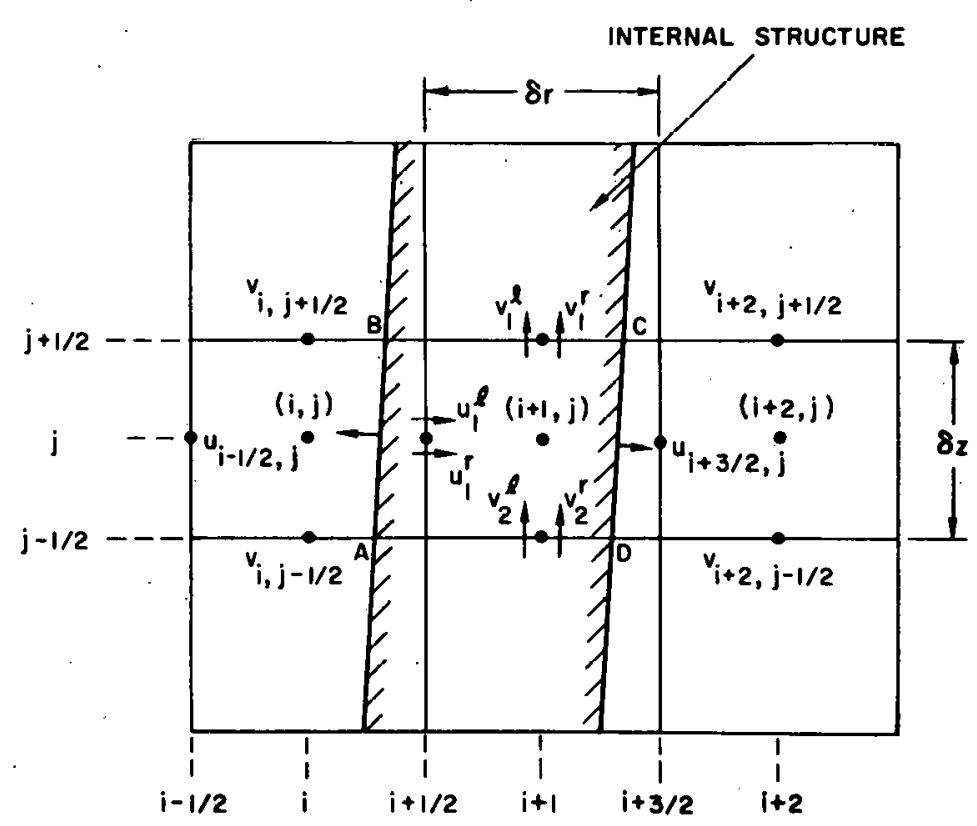

Fig. 14

Eulerian Finite-difference Mesh with Multivalued Field Variables Adjacent to the Thick Internal Structure. ANL Neg. No. $300-78-927$.

Although at the present time the method still cannot treat the thin structure surrounded by fluid, it can be easily generalized to handle the thin component based on the scheme outlined above. For instanre, if the cell $(i, j)$ 
contains the core barrel as shown in Fig. 15, then the fluid variables should have two sets of value. The variables $\mathrm{p} l, \rho l, \mathrm{u}^{l}$, and $\mathrm{v}^{l}$ are calculated in such a way that the fluid on the left-hand side of the core barrel slides tangentially. Likewise, $\mathrm{p}^{\mathrm{r}}, \mathrm{\rho}^{\mathrm{r}}, \mathrm{u}^{\mathrm{r}}$, and $\mathrm{v}^{\mathrm{r}}$ are obtained so that the fluid on the right-hand side also moves tangentially.

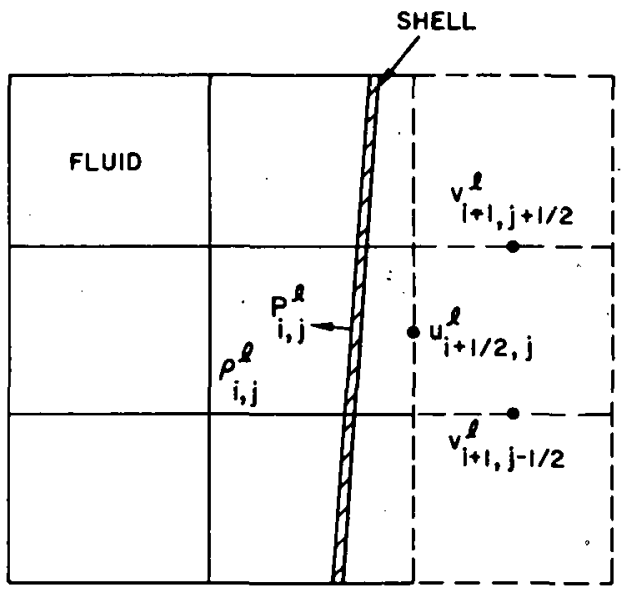

LEFT

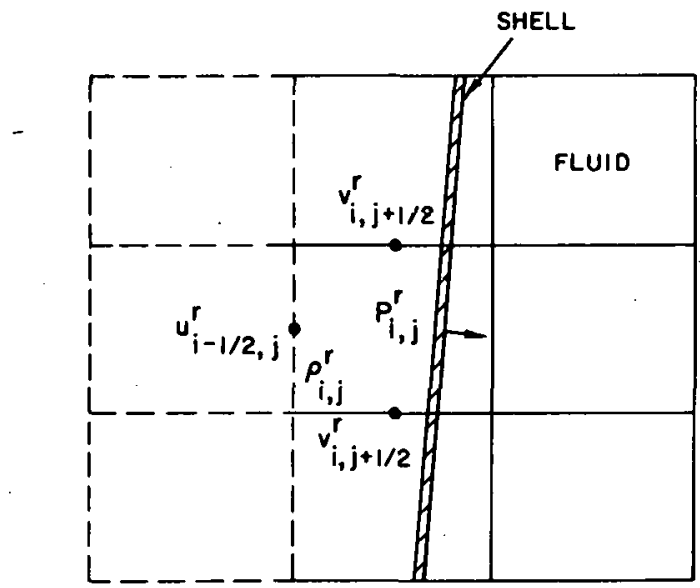

RIGHT

Fig. 15. Eulerian Finite-difference Mesh with Multivalued Field Variables Adjacent to the Thin Internal Structure. ANL Neg. No. 900-78-921.

Similar to the cases mentioned above, field variables can be obtained for the fluid located at the top or bottom of the structure. Thus, a cell can have up to four sets of field variables. Also, it should be mentioned that we have to extrapolate the velocities far enough so that velocities needed for. moving the particles around the structure are available.

In general, the multivalued pressure fields are determined by the sliding conditions; the density fields are calculated from the equation of state; the velocity fields are obtained from the mass equation as well as the inviscid conditions outlined above. For those variables (such as the densities if one wishes to use the complete mass equation) at the exterior side of the Eulerian cell which cannot be computed by the conservation equations, extrapolation of their values from the interior region is necessary.

\section{Particle Movement near Corner}

After solving for the advanced-velocity field and other field variables, a new configuration of the flow field is generated by moving the particles to their new positions. Since particle-velocity components is obtained by averaging from the velocities at the nearest four locations, care should be taken for the particle movement near the corner and other irregularities. Figure 16 shows an internal structure submerged in the fluid together with the velocity field required for moving particles around the corner. Thus, for 


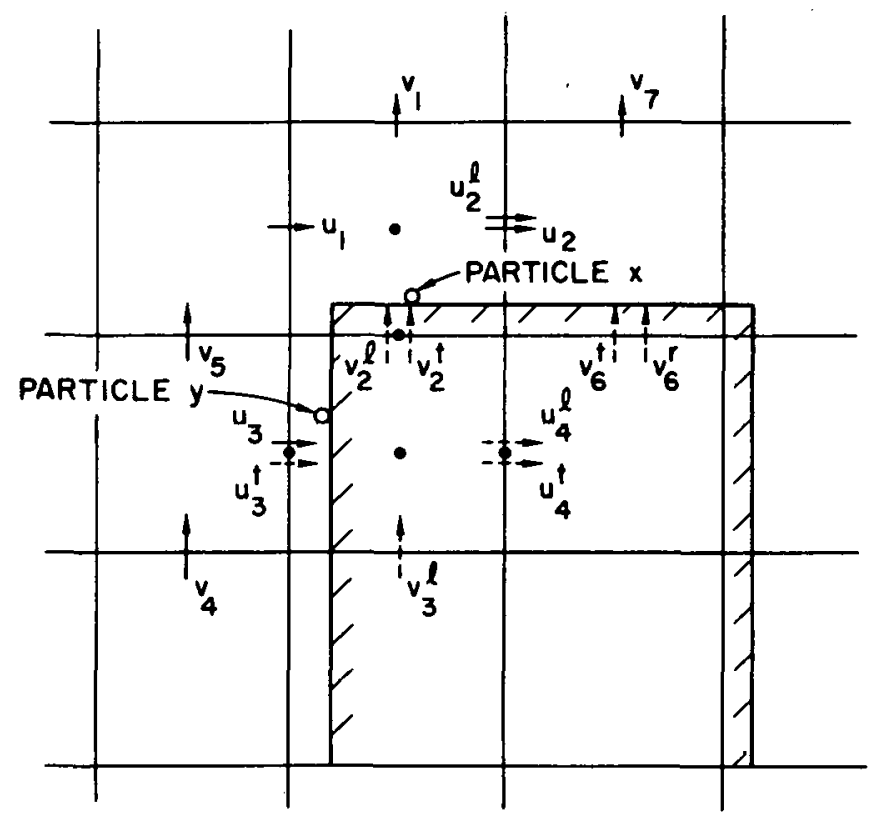

Fig. 16. Particle Velocities near the Corner. ANL Neg. No. 900-77-1852. a particle located above the structure, such as particle $x$, we use $u_{1}, u_{2}, u_{3}^{t}$, and $u_{4}^{t}$ to compute $u_{x}^{n+1}$; we use $v_{1}, v_{2}^{t}, v_{6}^{t}$, and $v_{7}$ to calculate $v_{\mathbf{x}}^{n+1}$. Similarly, for a particle located at the left-hand side of the structure, say particle $y$, we use $u_{1}, u_{2}^{l}, u_{3}$, and $u_{4}^{l}$ to calculate the $u_{y}^{n+1}$; we use $v_{2}^{\ell}, v_{3}^{l}, v_{4}$, and $v_{5}$ for the calculation of $v_{y}^{n+1}$.

D. Moving Cover and Coolant

The Eulerian hydrodynamics is ideal for long duration calcula tions for problems truvolving lárge material distortions. The basic ICE technique has an option for treating inflow and outflow boundary conditions. However, the size of

the wall opening in the basic ICE method is limited to multiples of the cell size. In other words, if the wall opening is small, the Eulerian cell dimension must also be made small. In addition, the size of the opening in the basic ICE technique must remain constant. Thus, the opening does not vary with time, which is different from a gap generated by the slug-impact force on the reactor head cover at the head-vessel junction. Therefore, the basic ICE technique must be expanded in order to treat the coolant spillage problem more realistically.

To accomplish this objective, a quasi-Eulerian method has been developed $^{14}$ and recently been incorporated into the ICECO-STR for treating the coolant spillages. In this scheme when the vessel head moves upward a set of irregular cells, whose size varies in the axial direction according to the head displacement, is introduced on the top of the full-zone regular cell, as shown in Fig. 17. Since in these irregular cells only the axial dimension of the cell varies, but the shape remains rectangular, it is possible to derive the

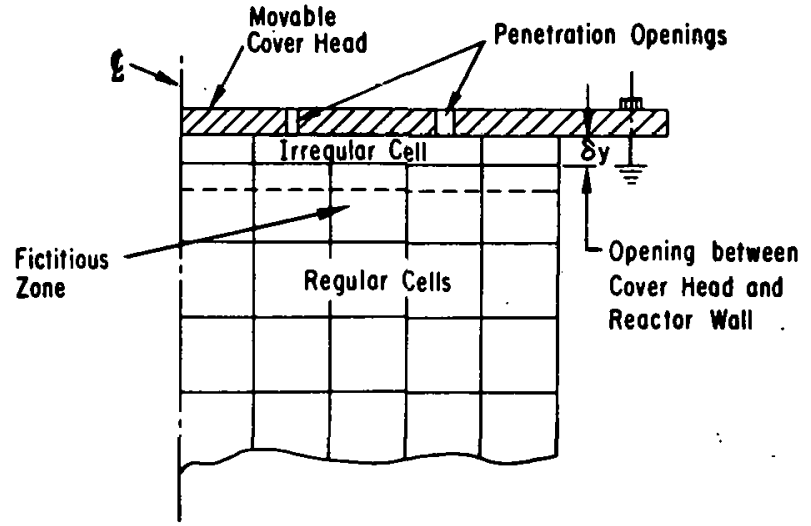

Fig. 17. Quasi-Eulerian Cell and Penetration Openings. ANL Neg. No. 900-77-1806 Rev. 1. governing differ ence equations with respect to these irregular cells. Here, the control-volume technique similar to the ICE technique is used, in which the conservation equations are generalized to take into account the penetration holes and the side opening. 'The tops 
of the quasi-Eulerian cells are considered as an inviscid boundary, moving with the same velocity as the cover head. Thus, separation of the entire coolant free surface with the reactor cover is not permitted after the slug impact.

For simplicity, it is further assumed that (1) the penetration opening is located on the top center of the quasi-Eulerian cell; (2) only one penetration is allowed for each cell; (3) the penetration is considered to become open when the impulse on this penetration area exceeds a certain input value. With these assumptions, a modified Poisson equation is obtained which has the form

$$
\begin{aligned}
p_{i, j}^{n+1}\left[\frac{1}{c_{i, j}^{n}}+2 \theta \varphi \delta t^{2}\left(\frac{1}{\delta r^{2}}+\frac{1}{\delta y^{2}}\right)\right] \\
\quad=H_{i, j}+\theta \varphi \delta t^{2}\left[\frac{r_{i-(1 / 2)} p_{i-1, j}^{n+1}+r_{i+(1 / 2)} p_{i+1, j}^{n+1}}{r_{i} \delta r^{2}}\right. \\
\left.+\frac{p_{i, j-1}^{n+1}+\eta_{i} p_{0 i, j+1}^{n+1}+\left(1-\eta_{i}\right) p_{i, j+1}^{n+1}}{\delta y^{2}}\right]
\end{aligned}
$$

whcrc $\eta_{j}$ is the ratio of the opening area to the cell area at the quasi-Eulerian cell $(i, j), p_{0 i, j+1}$ is the pressure outside the opening, $\mathrm{H}_{i, j}$ is the source term of the Poisson equation, which is a function of the momentum source terms, opening ratio $\eta_{i}$, and the opening velocity $v_{0}$, as well as the cover velocity at the $\mathrm{n}^{\text {th }}$ cycle.

E. Simultaneous Iteration

We have presented the equations governing the advanced-pressure field for the entire computing domain. In summary, the governing difference equations used in different cells for a typical Eulerian mesh shown in Fig. 1 are

(1) Poisson equation (i.e., Eq. 17) for the full cell (F);

(2) Relaxation equation (Eq. 22) for the external boundary cell (B);

(3) Generalized relaxation equation (Eq. 27) for the internal boundary cell (IB);

(4) Modified Poisson equation (i.e., Eq. 32) with modified source terms of the momentum equations and pressure equation for the quasiEulerian cell (Q).

In the analysis, Eqs. 17, 22, 27, and 32 are solved together by the regular iterative technique, which sweeps through all the regular and irregular cells in the directions of increasing $i$ and $j$. During each iteration 
sweep, say at iteration cycle $h+l$, the new value of $\left(p_{i, j}^{n+1}\right)^{h+1}$ is obtained either from Eq. 17, 22, 27, or 32 and is used to replace the old value of $\left(p_{i, j}^{n+1}\right)^{h+1}$. The iteration is terminated when the new values do not differ much from the old values. In other words, the convergence is achieved when

$$
\left|\frac{\left|p_{\text {new }}^{n+1}-p_{\text {old }}^{n+1}\right|}{\left|p_{\text {new }}^{n+1}+p_{\text {old }}^{n+1}\right|}\right| \leq \epsilon
$$

has been satisfied for all cells. Here $\varepsilon$ is usually of the order $5 \times 10^{-4}$ or equal to some other suitable small number.

Because the source term of the relaxation equation at the fluid-strurture interface is proportional to the mass flux, the pressure, density, and velocity fields must be iterated simultaneously. Thus, after each iterate giving the pressure field, the density and velocity fields are immediately computed by the equation of state and the momentum equations, respectively. Based upon the new density and velocity, the mass flux at the interface is appropriately adjusted, which results in a new pressure in the boundary cell. This procedure is repeated until the boundary conditions at all interfaces are rigorously satisfied.

For problems involving a movable head or coolant spillage we first calculate the cover velocity, using the iterated pressure force exerted on the cover head. Then the pressure above the quasi-Eulerian cell is computed, using the axial momentum equation in which the penetration opening $\eta_{i}$ is assumed to be zero: Finally, the new iterated pressure $p_{i, j}^{n+1}$ is calculated. This procedure is repeated until Eq. 33 is also satisfied for every quasiEulerian cell.

Figure 18 is a flow chart representing the computational procedure.

F. Structural Dynamics

Lagrangian coordinate systems are employed in the structural-dynamic analysis. Because of complicated structure components involved in a typical reactor configuration, several separate programs. are employed for analyzing the structural response. In the analysis of the plug-jump and sodium-spillage problem, the motion of the reactor head, which is assumed to have only rigidbody motion under the constraint of the holddown bolts, is calculated by a finite-difference program. Two other programs, one using a finite-element formulation and the other using a finite-difference approach, are discussed briefly in the following.

\section{Finite-element Structural Program}

The responses of containment strurtures surh as the radial shield, the core barrel, the core support structure, and the primary vessel can be 


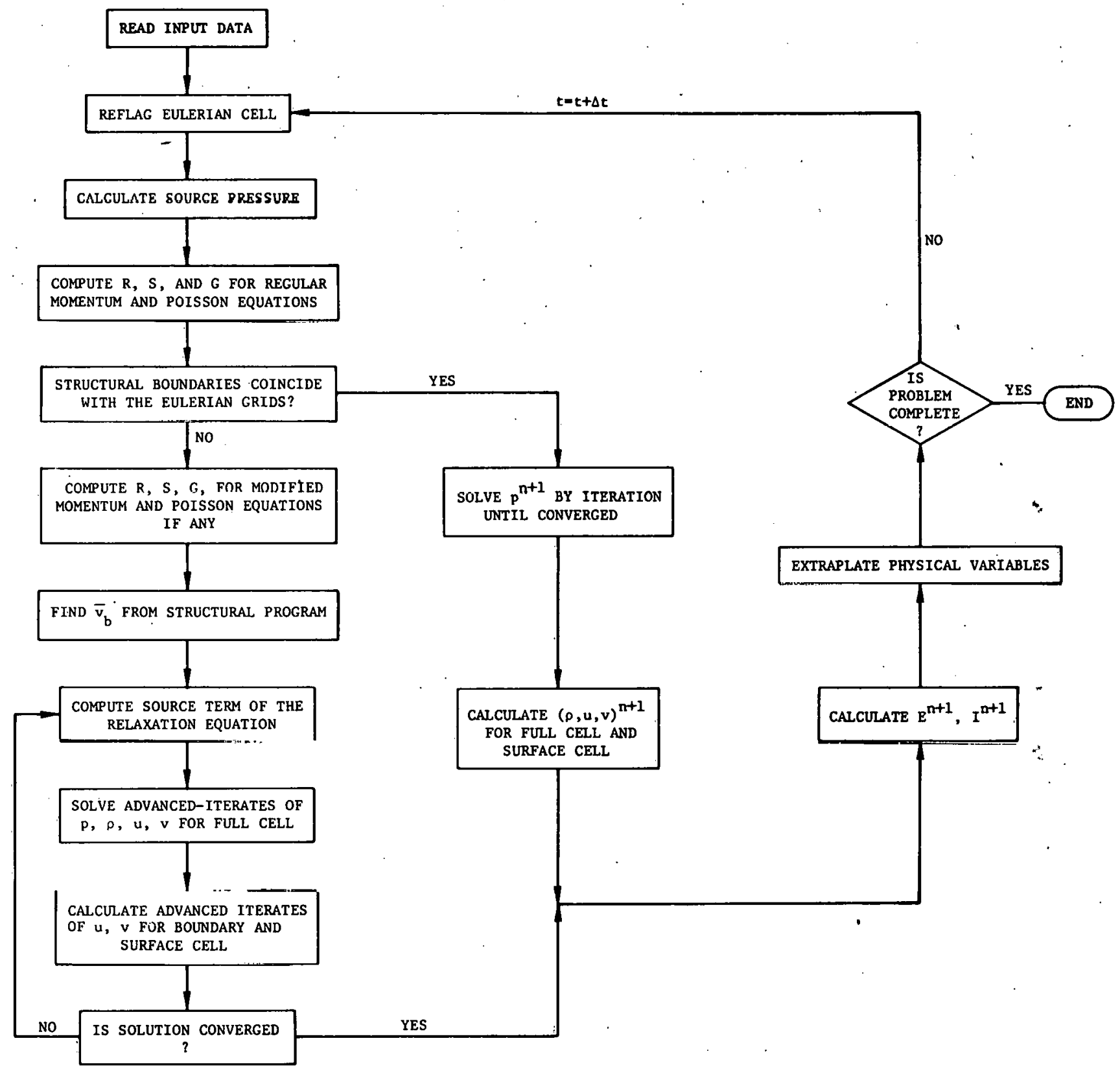

Fig. 18. Flow Chart Representing the Computational Procedure. ANL Neg. No. 900-78-919. 
analyzed by a modified version of finite-element program. ${ }^{15,16}$ This program used a Lagrangian (or convective) coordinate scheme in the numerical analysis and is best suited for large-displacement, small strain, elastic-plastic dynamic problems.

In this scheme Lagrangian coordinates of the element rotate but do not deform with the elements. The strain is linearly related to the displacement of the element relative to the Lagrangian coordinates. Similarly, the nodal forces are linearly related to the element stresses. The original program, WHAM, has the conical-shell element and axisymmetric triangle element which can be used to model the complicated structural components.

The displacement field of the shell element consists of cubic transverse displacements and linear axial displacements. Resultant forces are computed by five-point numerical integrations across the depth of the element. The triangle continuum element uses linear displacement fields. It can be used to simulate fluid or elastic-plastic solid. Recently, a quadrilateral fluid element and a quadrilateral elastic-plastic element have been added to the program.

\section{Finite-difference Shell Program}

A finite-difference thin-shell program has been used previously in analyzing the response of the primary vessel. This program is now available as an option to the WHAM program to another version of ICECO. The differential equations of dynamic equilibrium of a shell of revolution (see Fig. 19) undergoing large deflections $\operatorname{are}^{17,18}$

$$
\begin{aligned}
& \frac{\partial}{\partial s}\left[N_{\varphi} r \cos \varphi\right]-\frac{\partial}{\partial s}\left[Q_{\varphi} r \sin \varphi\right]-N_{\theta}+p r \sin \varphi-\operatorname{mr} \ddot{r}=0 ; \\
& \frac{\partial}{\partial s}\left[N_{\varphi} r \sin \varphi\right]+\frac{\partial}{\partial s}\left[Q_{\varphi} r \cos \varphi\right]-\operatorname{pr} \cos \varphi-m r \ddot{z}=0 ; \\
& \frac{\partial}{\partial s}\left[M_{\varphi} r\right]-M_{\varphi} \cos \varphi-Q_{\varphi} r=0,
\end{aligned}
$$

where $s$ is the length of the shell along the meridian, measured from the vertex of the shell, $m$ is the mass of the shell per unit area, $\varphi$ is the angle of inclination of the element with respect to the $r$ direction, $p$ is the pressure, $\mathrm{N}_{\varphi}$ and $\mathrm{N}_{\theta}$ are two tangential stress resultants, and $Q_{\varphi}$ is the transverse stress. The shell is idealized by layers of subshells that can carry only normal stresses in the planes parallel to the tangential plane of the shell structure. These subshells are connected by the material that carries only shears. The vessel material is considered to be elastic-plastic and strain-hardening. The strain-hardening shell is represented by a model in which the thickness of the subshell is further decomposed into subregions of elastic-perfectly-plastic materials having different yield stresses, but common strains. The von Mises yield condition is used. 


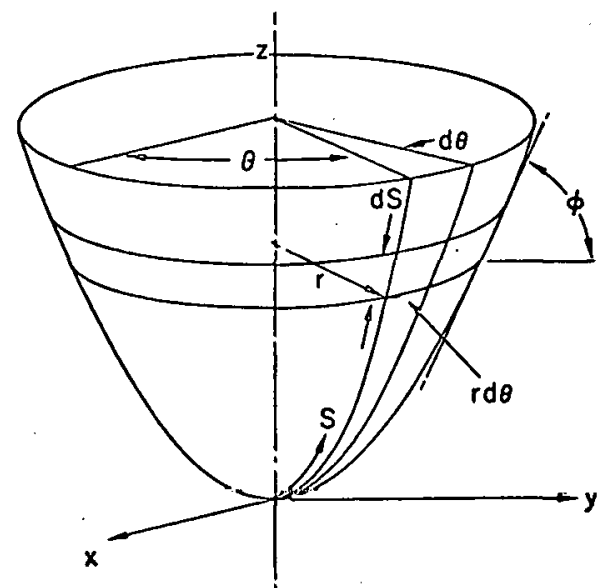

(a)

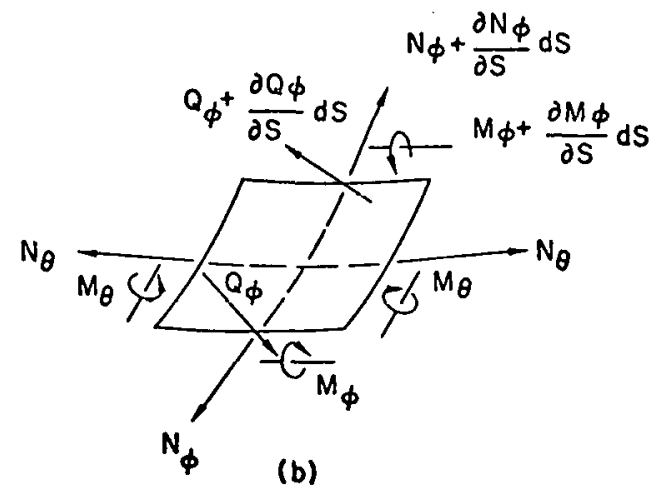

rig. 19

Shell of Revolution and Free-body Diagram. ANL Neg. No. 900-75-523.

\section{G. Numerical Stability}

For the consideration of numerical stability, the time step $\delta t_{h}$ chosen for the hydrodynamic analysis must satisfy the modified "Courant Condition." The restriction is that fluid must not be permitted to flow across more than one computational cell in one time step, that is,

$$
\delta t_{h}<\min \left(\frac{\delta r}{|u|_{\max }}, \frac{\delta z}{|v|_{\max }}\right)
$$

Since in the plug-jump (movable-head) problem the axial dimension of the quasiEulerian cell varies with the head displacement and is much smaller than the axial dimension of the regular cell, the time step used at the inception of slug impact is further restricted by

$$
\delta t_{h}<\frac{\delta y}{\left|v_{y}\right|_{\max }}
$$

where $\delta y$ is the axial dimension of the quasiEulerian cell and $v_{y}$ is the axial velocity component in the quasi-Eulerian cell.

For the coupled fluid-structure analysis, the time step $\delta t_{s}$ employed for the structural dynamic program must satisfy the following requirements:

$$
\delta t_{s}=\beta \frac{l}{c_{\ell}}
$$

and

$$
\delta t_{s}=\beta \frac{l}{6 c_{b}} \text {. }
$$

Equation 37 applies to all elements, Eq. 38 only to flexural shell elements. Here $\beta$ is a reduction factor usually between 0.5 and 0.8 ; $l$ is the distance between two nodes; $c_{\ell}$ and $c_{b}$ are longitudinal and flexural wave velocities, respectively, and are defined in Ref. 16.

Because the hydrodynamir program uses an implicit integration scheme while the structural dynamic program utilizes an explicit integration procedure, 
$\delta t_{h}$ is larger than $\delta t_{s}$. 'Whus, within each time step several structural dynamic calculations must be performed in order to match one hydrodynamic calculation. The number of structural calculations (or subcycles) $N$ can determined by

$$
N=I\left(\delta t_{h} / \delta t_{s}\right)+1
$$

where I denotes the integral part of the ratio.

In certain circumstances, the viscosity coefficients $\lambda$ and $\mu$ should be used to damp out the pressure oscillation, particularly in a high-energy excursion. Thus, similar to the treatment of the ICE technique, the coefficients $\lambda$ and $\mu$ should be large enough so that

$$
\lambda, \mu \geq 3 / 2 \rho|v|^{2} \delta \mathrm{t}+\rho_{\max }(\nabla \cdot \mathrm{v})\left(\delta \mathrm{r}^{2}, \delta \mathrm{z}^{2}\right)_{\max }
$$




\section{SAMPLE PROBLEMS}

\section{A. Bubble-Coolant Interaction}

Although the Eulerian hydrodynamic method has been coupled together with the Lagrangian structural-mechanics technique for analyzing the problem of the fluid-structure interaction, the program still is very flexible. It can be used for purely hydrodynamic analysis in which the structural-dynamic calculation is completely bypassed. To illustrate the capability of the basic hydrodynamic code, a problem concerning bubble-coolant interaction is presented. Figure 20 depicts the initial configuration with initial core pressure equal to $9.8 \mathrm{MPa}$. In this configuration the bottom part of reactor containment is removed to simplify the analysis. All solid structures are assumed to be rigid with thei $r$ boundaries coinciding with the fixed Eulerian grids. The radial shield is simulated by the rigid obstacles.

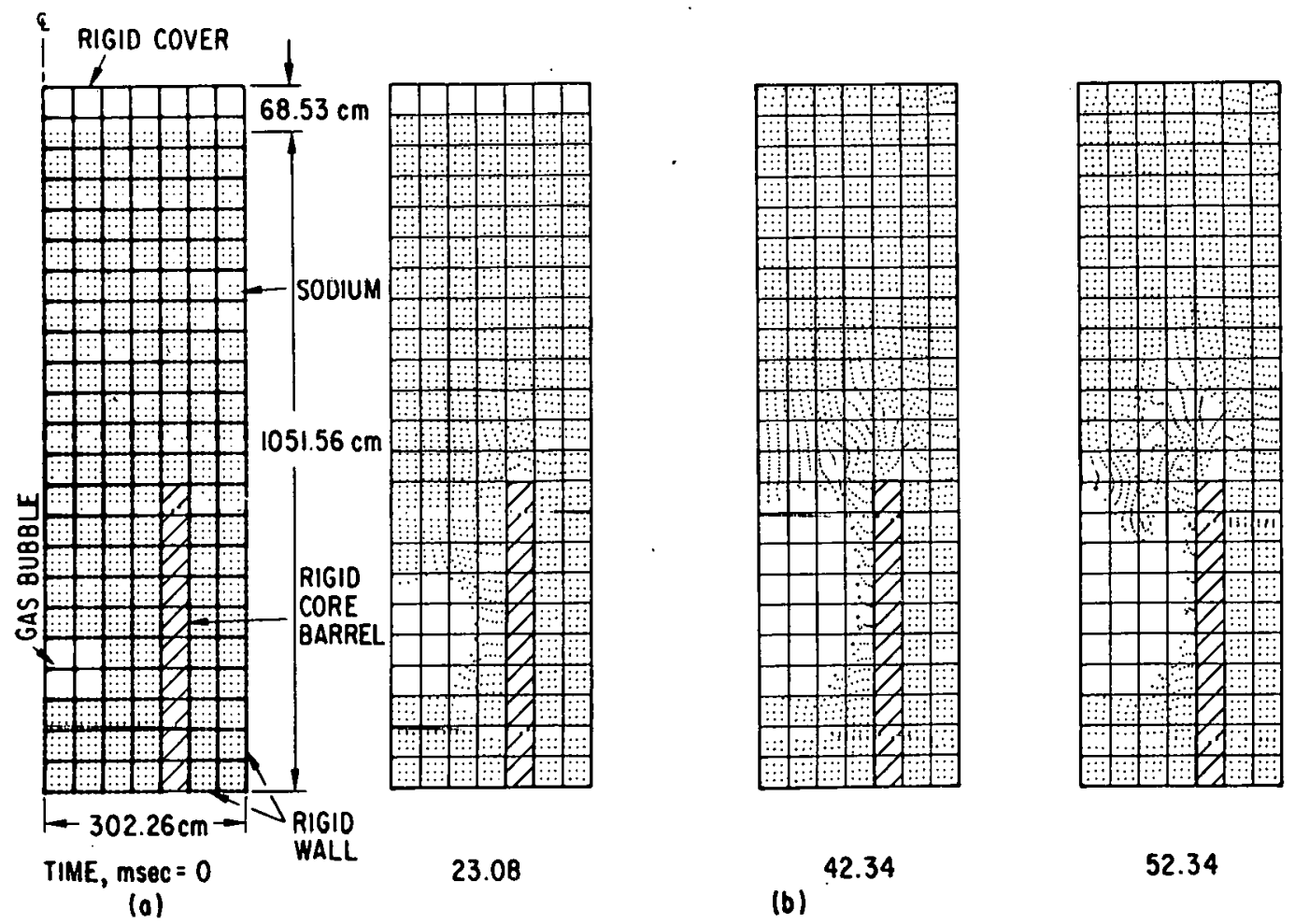

Fig. 20. Bubble Motion and Coolant Configuration at Different Times. ANL Neg. No. 900-3452 Rev. 2.

Figure 20 presents the bubble motion and coolant configuration at three different times. Before the slug impact, the bubble shape was not spherical, but rather toroidal. After the slug impact, an intense pressure wave traveled back into the coolant, which greatly distorted the interface and generated a spike near the top surface of the bubble. The formation of this spike can be inferred by the mechanism of the Taylor instability. The continuing growth of this spike may cause bubble collapsing and turbulent mixing. The peak force exerted on the vessel cover is approximately $1.85 \mathrm{GN}$ (185 $\mathrm{x}$ $10^{12}$ dynes). 
Several calculations have been performed by varying the excursion magnitude and configuration. Results reveal that, in all cases studied, if the initial bubble position is not too high relative to the initial position of the free surface, the bubble will not surface upward, but collapse. The reason for the bubble collapse is that it cannot sustain the reflected pressure loading in the sur rounding coolant.

B. Wave Propagation in a Straight Pipe

This work deals with the response of a straight pipe in which the pipe wall is treated as elastic-plastic material. The effect of pipe-wall deformation on pressure-wave attenuation is also studied.

'The mathematical model used in the analysis is a $3-\mathrm{ft}(91.44-\mathrm{cm})-1$ ong pipe made of stainless steel (see Fig. 21). A constant pressure of $4.2 \mathrm{MPa}$ was imposed at one eind of the pipe, the

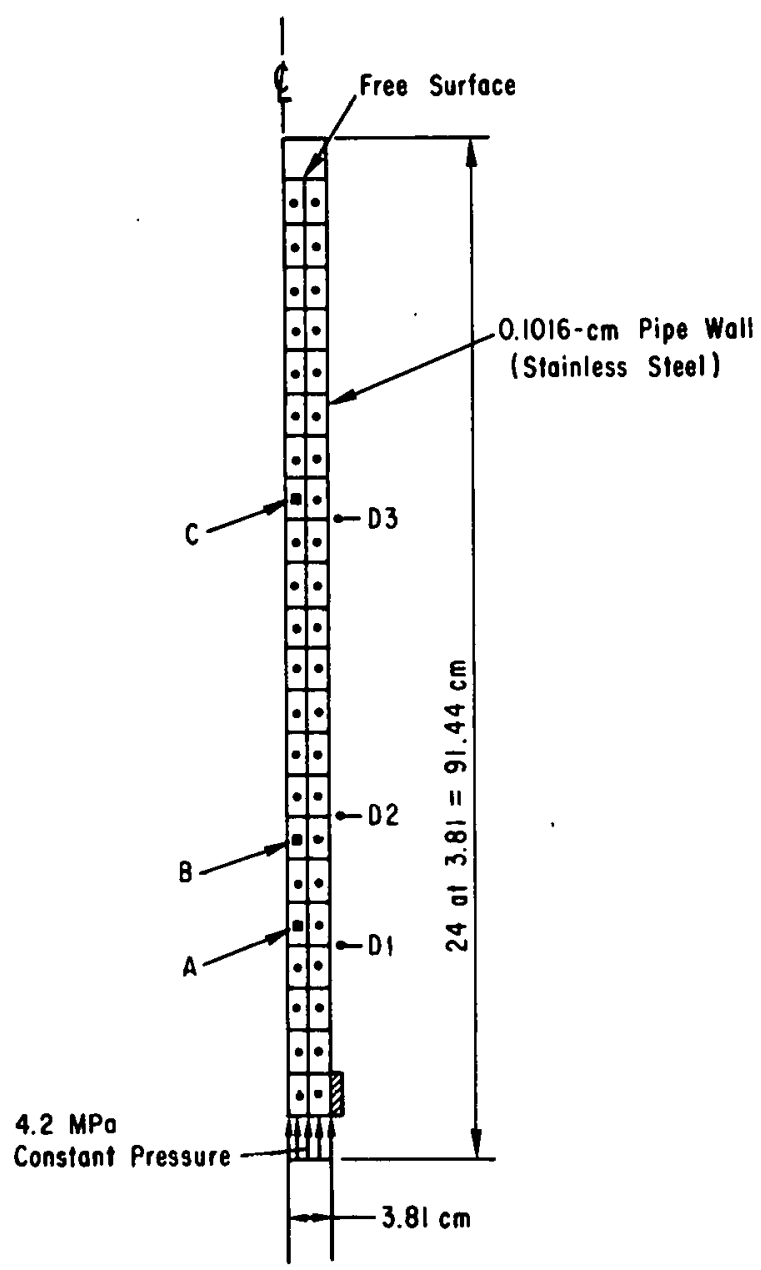

Fig. 21. Mathematical Model and Configuration of Elastic-Plastic Pipe Used in the ICECO Analysis. ANL Neg. No. 900-78-922. other end being assumed to be a free surface. To understand further the effect of wall deformation upon the pres sure attenuation, a rigid-wall calculation was also made.

Figure 22 shows calculated pressure histories at locations $A, B$, and $C$ indicated in Fig. 21 for both rigid and elastic-plastic pipes. In the rigid-wall analysis, the peak pressures are about 4.2 MPa; this corresponds to the peak value of the input pulse. However, in the elastic-plastic-wall analysis, the peak pressures change significantly. At positions close to the source, such as $A$ and $B$, the computed peak pressures are lower than the input pressure, but higher than the yield pressure (about. $3.4 \mathrm{MPa}$ ) of the pipe wall. At positions away from the source, the peak pressures are attenuated, and their values are less than the yield pressure, as indicated for location $C$. The wall deformation also has an effect of delaying the loading time of the pressure pulse. The pressure histories obtained in the elastic-plasticwall calculation are fairly smooth. The small oscillation observed is probably due to the response of the pipe wall. 

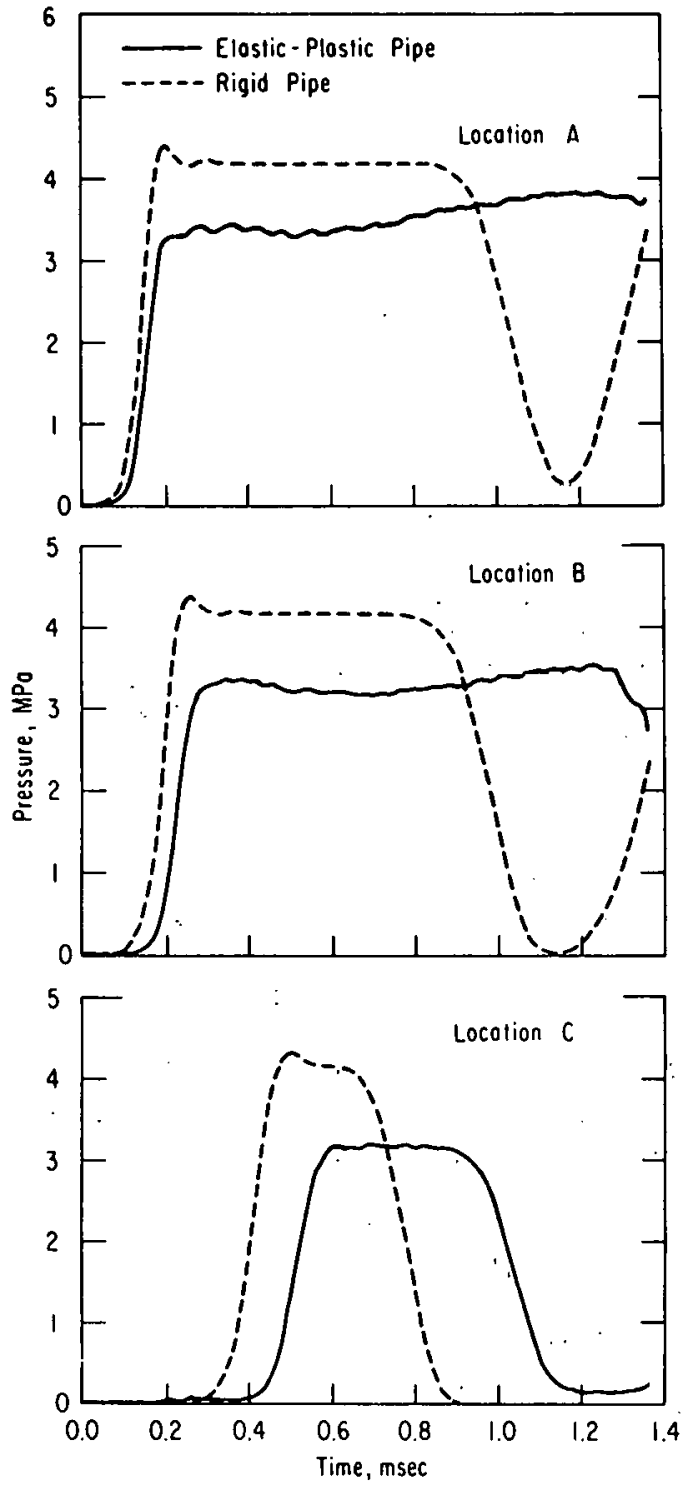

Fig. 22. Calculated Pressure Histaries at Locations $A, B$, and $C$. ANL Neg. No. 900-78-918.
This type of oscillation can probably be eliminated by introducing the structural damping in the shell subroutine.

Figure 23 shows the radial deformations as a function of time at the three locations D1, D2, and D3 indicated in Fig. 21 . Plastic deformations resulting from the transient pressure loading take place near the source region.' At downstream positions, only elastic deformations are noticed, as shown in Fig. 23. This is because the pres sure loading at downstream positions are below the yield pressure.

\section{Response of the Primary Containment}

Figure 24 is the configuration of the primary containment used in the analysis. Features included are: (1) core, (2) core-support structure, (3) coolant passage holes in the core-support structure, (4) core barrel, (5) reactor vessel with curved bottom, (6) cover gas above the coolant, and (7) rigid vessel head. The reactor-vessel material is elastic-plastic and strain-hardening. The core barrel and core-support structure are assumed to be rigid. The energy release in the core was characterized by a pressure-volume relationship, which has an initial pressure of 20.4 MPa and decays exponentially.

The reactor configurations at three different times are shown in Fig. 25. The expansion of the gas bubble, the movement

of the coolant, as well as the deformation of the reactor vessel can be clearly seen. These configurations reveal strong disturbances at the upper edge of the core barrel, which will cause severe zone distortions in the Lagrangian analysis. They also show different fluid motion at two sides of the core barrel. At the left-hand side the fluids slide along the core barrel; at the right-hand side the fluids remain relatively undisturbed. It is also noted that a sufficiently large amount of coolant has been pushed downward through the coolant passage holes into the lower region of the reactor vessel to cause the coolant pressure below the core-support structure to increase considerably. The phenomena of wave transmission and mass transfer between the upper and lower reactor plena are very difficult to analyze by the conventional Lagrangian method. 


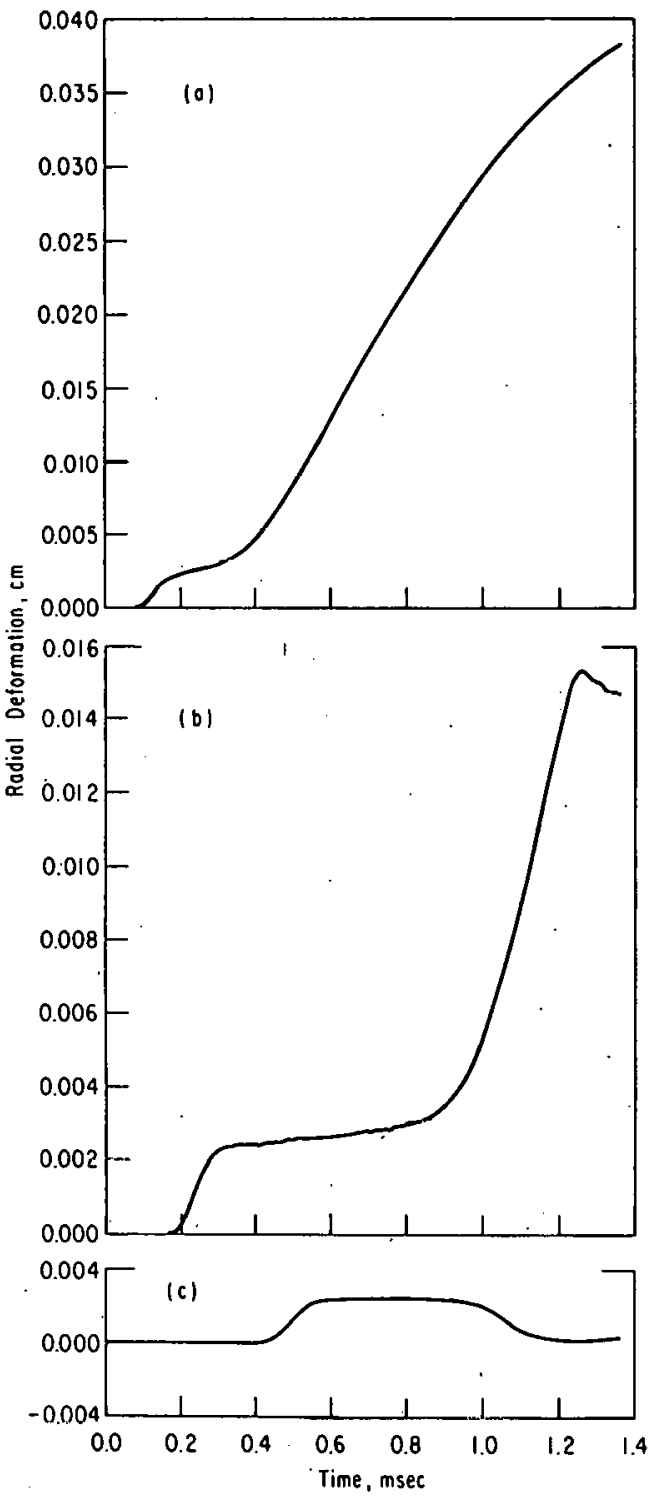

Fig. 23. Radial Deformations as a Function of Time at Locations D1, D2, and D3. ANL Neg. No. 900-78-915.

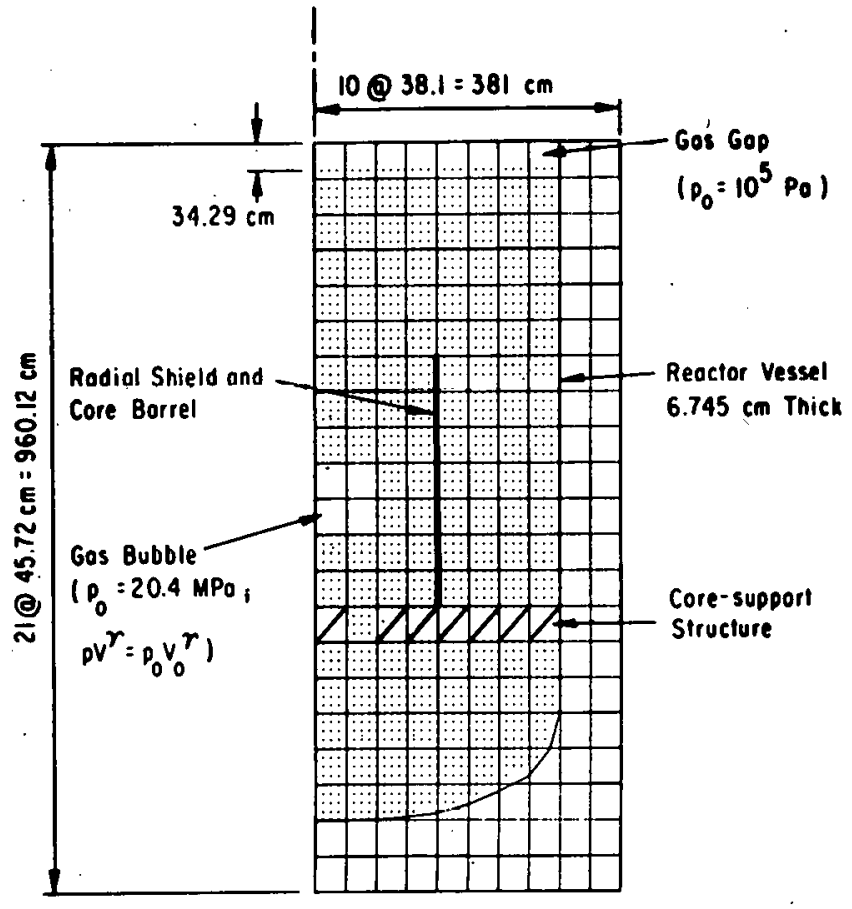

Fig. 24. Initial Configuration of the Primary Containment Used in the Analysis. ANL Neg. No. 900-76-53 Rev. 


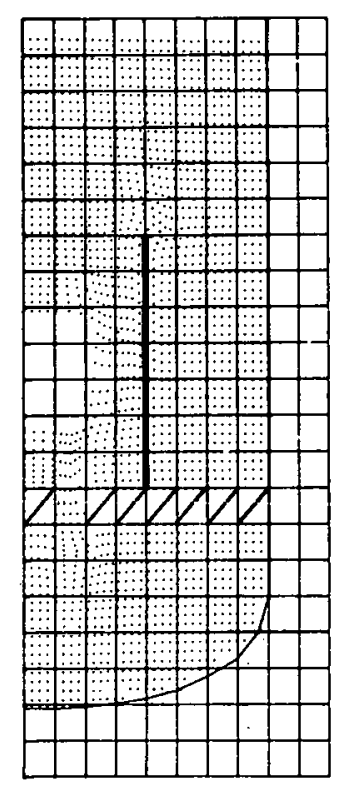

$t=8.3 \mathrm{~ms}$

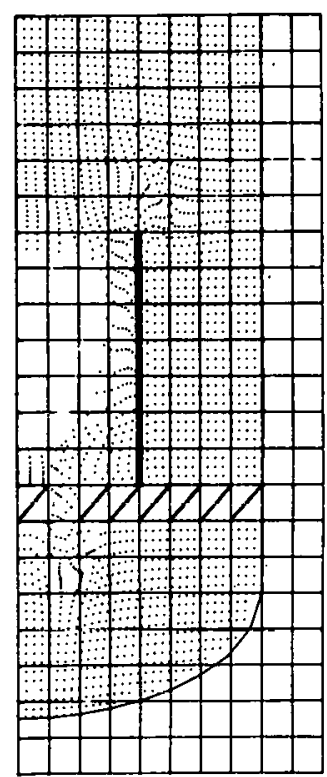

$t=17.3 \mathrm{~ms}$

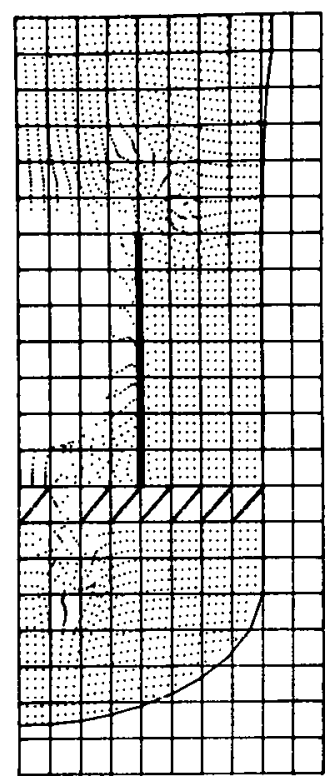

$t=26.3 \mathrm{~ms}$

Fig. 25. Reactor Configurations at Three Different Times. ANL Neg. No. 900-76-54.

D. Simulation of the Excursion Model

In order to validate the analysis of the two-dimensional fluid-structure interaction, a comparison of code prediction with experimental data was made. The configuration of the reactor containment vessel is shown in Fig. 26, which

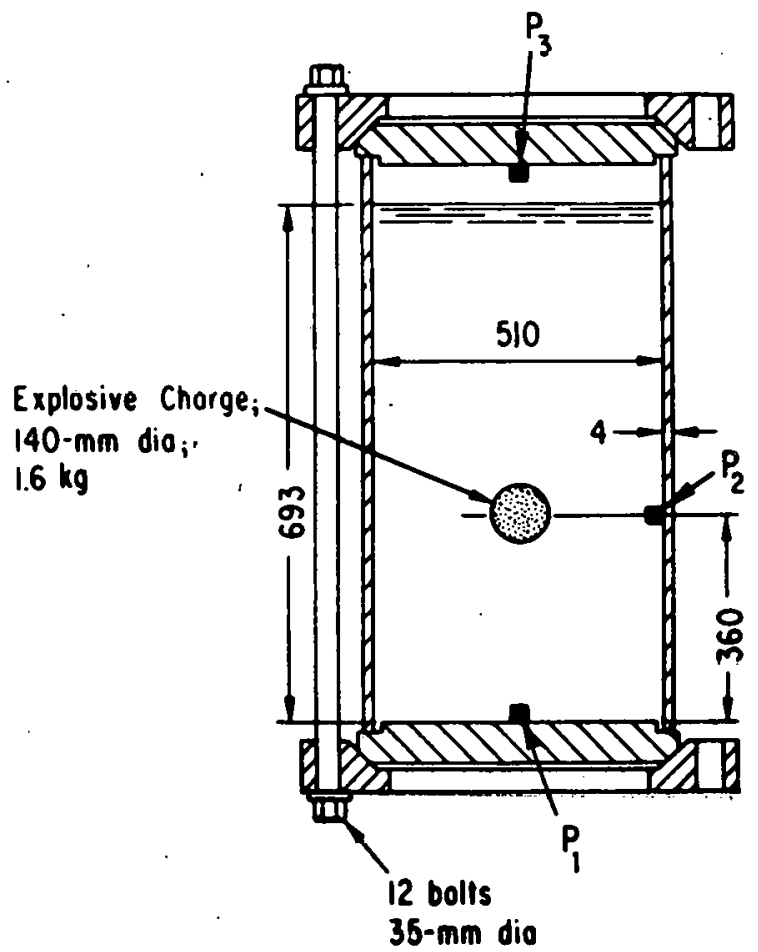

Fig. 26

Model Test Configuration for the Containment Studies. ANL Neg. No. 900-78-926. 
was a scaled test model of the German Demonstration Plant SNR -300 . The basic test configuration consists of a spherical pressure-volume source immersed within a pool of water, which in turn is held by a cylindrical container; the space is occupied by air. The cylindrical walls of the container are precompressed by the rigid end plates with holddown bolts. Rubber seals separate the cylindrical walls from the end plates.

In the analytical model shown in Fig. 27(a) a spherical-shaped source is used to represent the explosive charge. The position of the outside cylindrical boundary corresponds to the mean radii of the vessel. Other assumptions considered in the analytical models which pertain to both test configurations are outlined below:

(a) The top and bottom boundaries are assumed to be stationary,

(b) The cylindrical vessel boundary at the bottom is constrained axially and is free to move radially,

(c) The top vessel boundary is assumed to be free of any constraints,

(d) The equation of state for air is

$p=\left(v_{0} / v\right)^{1.3}$,

where $p$ is in atm, $v$ is the volume, and $v_{0}$ is the initial volume.

(e) Sodium spillage is neglected so that the results can also be compared with REXCO-code predictions.

TIME $=0 \mathrm{~ms}$

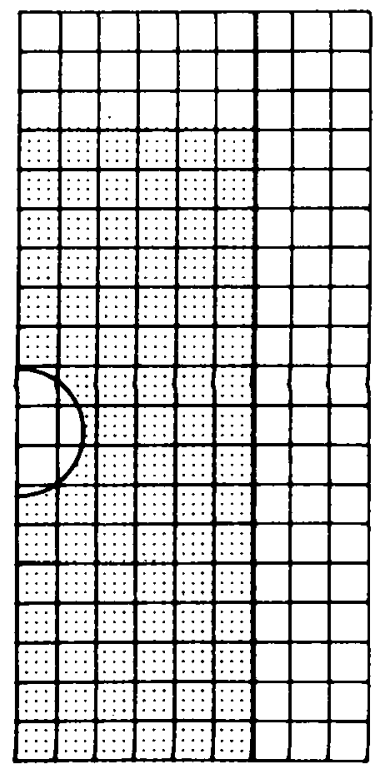

(0)
1.457

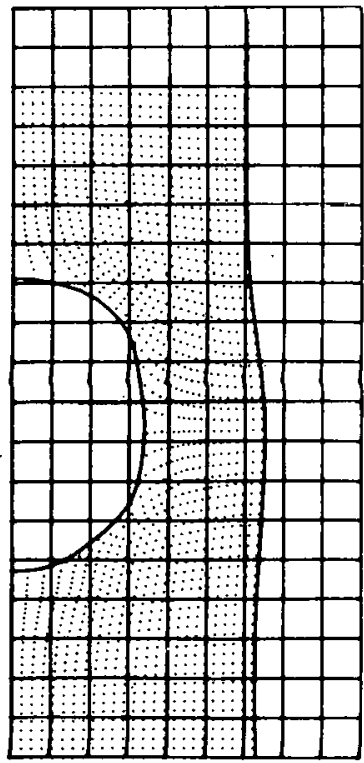

(b)

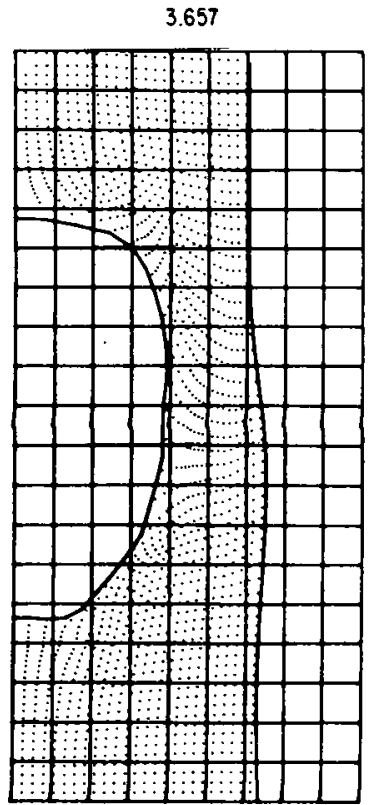

(c)

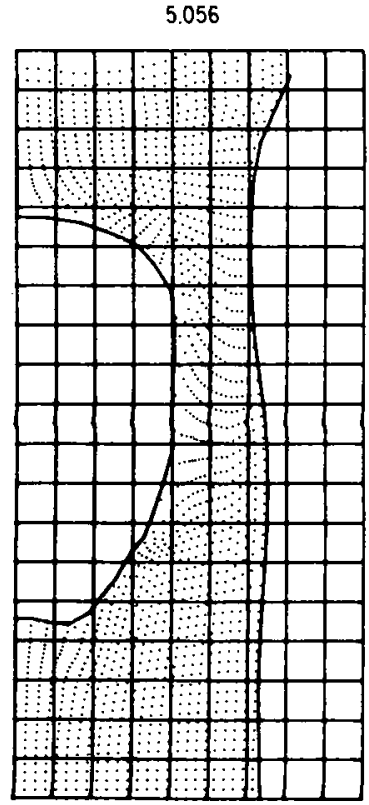

(d)

F1g. 27. Configurations of Thin-vessel Test. ANL Neg. No. 900-77-275. 
The stress-strain curve assumed for the thin vessel was confined to a bilinear representation. The elastic portion with modulus $E=20,000 \mathrm{~kg} / \mathrm{mm}^{2}$ extends to the stress of $44 \mathrm{~kg} / \mathrm{mm}^{2}$; beyond the yield stress, a plastic modulus $E_{p}=40.96 \mathrm{~kg} / \mathrm{mm}^{2}$ was as sumed.

The pressure-volume source characteristics used with the model are taken from Ref. 19 and given in Table $I$.

TABLE I. Source Characteristics for the Thin-vessel Model

\begin{tabular}{cc|cc}
\hline $\begin{array}{c}\text { Pressure, } \\
\mathrm{MPa}\end{array}$ & $\begin{array}{c}\text { Volume Ratio, } \\
\mathrm{V} / \mathrm{V}_{0}\end{array}$ & $\begin{array}{c}\text { Pressure, } \\
\mathrm{MPa}\end{array}$ & $\begin{array}{c}\text { Vuluice Ratio, } \\
\mathrm{V} / \mathrm{V}_{0}\end{array}$ \\
\hline 42.6 & 1 & 2.2 & 8 \\
38.0 & 1.18 & 1.2 & 12 \\
27.8 & 1.60 & 0.7 & 18 \\
19.9 & 2.12 & 0.3 & 28 \\
11.1 & 2.75 & 0.1 & 45 \\
7.1 & 3.47 & 0.1 & 68.5 \\
4.2 & 5 & & \\
\hline
\end{tabular}

Figurc $27(b)$ to (d) shows the reactor configurations at several different times, illustrating the displacement of the cylindrical wall and the motion of the fluid. As can be seen, the cylindrical wall has undergone large displacements. As it moves across the Eulerian cells, it intersects the fixed Eulerian grid lines in many different ways. Complex procedures would be needer if the sontrol-volume method were used in the solution of the problem.

The displacements of the thin vessel are characterized by plastic response. This deformation consists of a rapid increase to a maximum and then settling to a final value. We observed from the analytical solution that deformation first takes place at the location opposite the source, where the distance from the source is the closest. While this deformation is still increasing, the bottom of the vessel begins to deform. When the displacement opposite the source deforms to its maximum, the vessel bottom still keeps deforming and then subsides, and eventually supersedes in magnitude the first deformation. It may be observed that at about $2.5 \mathrm{~ms}$ the bottom part of the vessel has deformed to its final value.

The range of the deformed region at the initial part of the excursion is limited. For example, the vessel at the fluid level deforms little, because of the comparatively low pressure being developed there. In fact, as the fluid begins to rise, the radial deformation at the top part of the vessel is minimal until slug impact takes place.

During impact of the slug, the top of the vessel begins to deform rather abruptly. This deformation continues and reaches an equilibrium value at about $5 \mathrm{~ms}$. The yield limit of the vessel is reached early, and the major response of the vessel continues in the plastic regime. 
The experimental displacement histories at two points of the vessel, taken from Ref. 19, are plotted in Figs. 28 and 29. Figure 28 shows the test and the analytical displacements of the vessel at the initial height of the source. The agreement of the results up to the failure of the gage is quite good. The permanent set of the point is slightly overestimated by the analysis. Figure 29 shows the vessel deformation at $4 \mathrm{~cm}$ from the bottom of the vessel, and the agreement between analysis and experiment appears to be quite good.

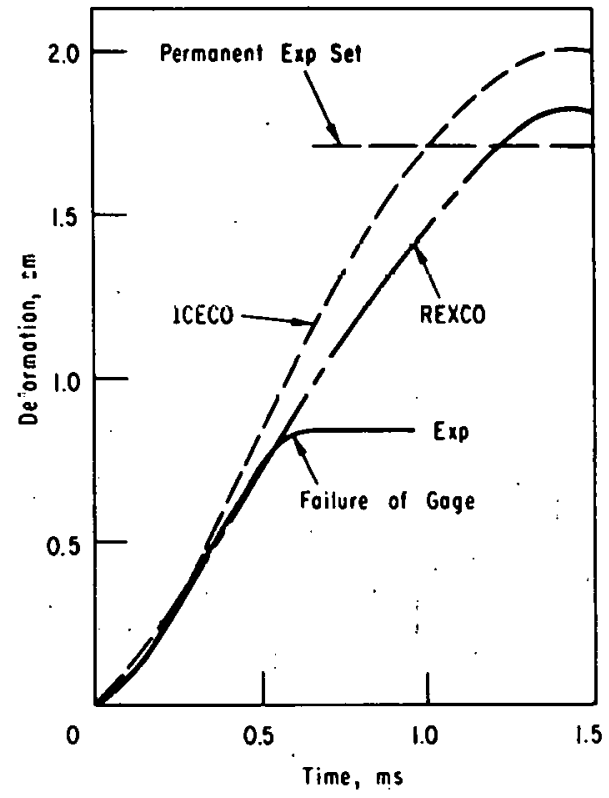

Fig. 28. Vessel Deformation at $z=36 \mathrm{~cm}$. ANL Neg. No. 900-78-923.

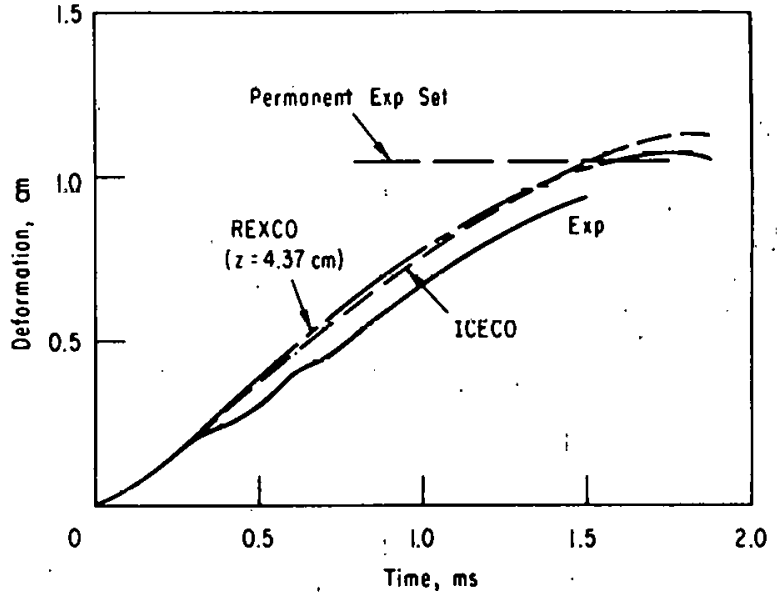

Fig. 29. Vessel Deformation at $z=4 \mathrm{~cm}$. ANL Neg. No. 900-78-925.

The permanent deformation of the thin vessel, also given in Ref. 19, is reproduced in Fig. 30, together with the corresponding analytical results. In general, the shapes of the experimental and analytical configurations are in good agreement. The displacement at the bottom of the vessel is overestimated in the analysis more than anywhere else along the vessel. This discrepancy may be attributed to the constraint of the boundary conditions of the model.

E. Responses of Structural Components

The response of a typical LMFBR primary containment to an HCDA was studied. The mathematical model, shown in Fig. 31, consists of the reactor core, coolant, radial shield, core barrel, core-support structure, and thc primary vessel. Since the shield material does not have tensile strength in the circumferential direction, it was considered as a compressible fluid with the same mass and compressibility as the actual material. The core-support structure was modeled as a composite structure made of plates and shells as in the actual structure. To simplify the analysis, the openings in the coresupport structure were not included in the model. Thus, the transmission of pressure pulses into the lower plenum depends solely on the downward motion 
of the core-support structure. The energy release in the reactor core was characterized by a pressure-volume relationship with an initial pressure of 20.4 MPa and was assumed to decay exponentially.

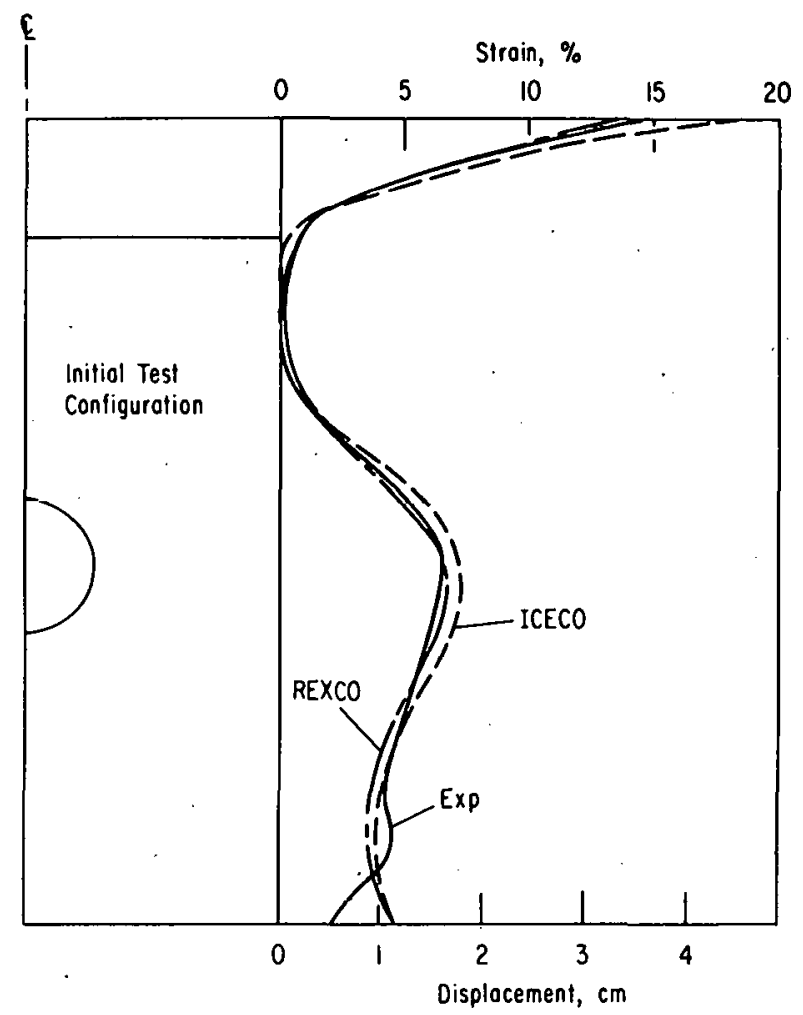

Fig. 30. Final Deformation of the Thin Vesse1. ANL Neg. No. 900-78-917.

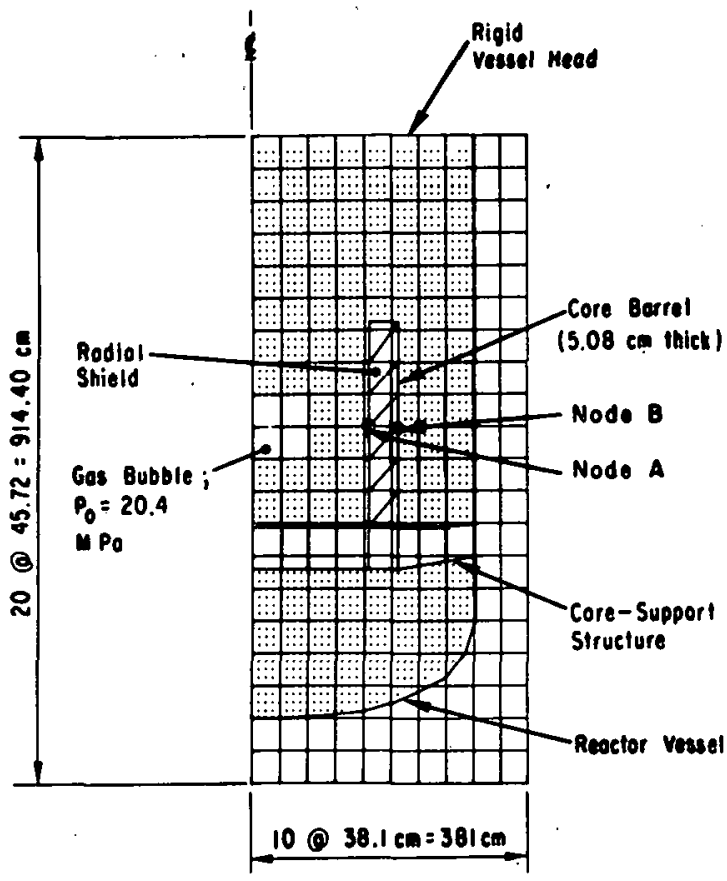

Fig. 31. The Mathematical Model Used for the Component-response Analysis. ANL Neg. No. 900-77-241B Rev. 1.

Figure 32 presents the reactor configuration at three different times. These configurations show the expansion of the core-gas bubble, the motion of the coolant, and the response of the core barrel, the core-support structure, and the primary vessel. They also show that the fluids slide along all the internal interfaces during the course of the motion. Note that fluids on both sides of the core barrel exhibit different motion. At the left-hand side, the fluid moves upwards along the radial shield; at the right-hand side, the fluid remains relatively undisturbed. Moreover, certain strong disturbances of the fluid motion occur at the upper end of the core barrel during the later stage of the excursion, which is believed to be induced by the vibration of the core barrel.

To illustrate the response of the containment structure, the axial displacements at the center of the core-support structure and the center of the primary vessel are given in Fig. 33. Due to the large pressure gradient be tween the upper and lower plena at the initial stage of the excursion, these structures are displaced downward and gradually attain their maximum dis placement. However, at a later stage of the excursion, the pressure in the upper plenum becomes small, which in turn causes the structures to be displaced upward. 


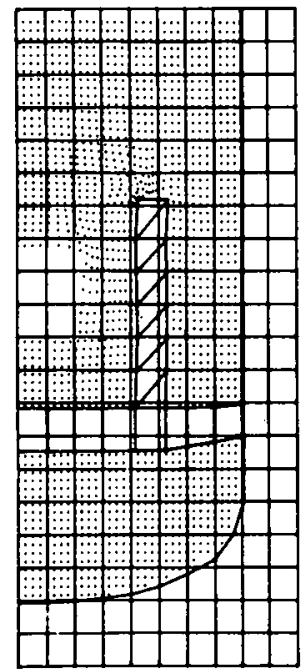

$t=6.8 \mathrm{~ms}$

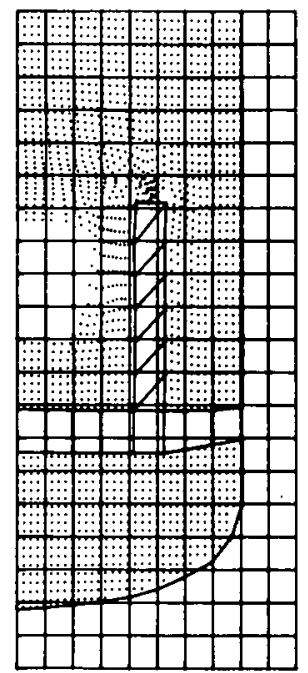

$1=11.3 \mathrm{~ms}$

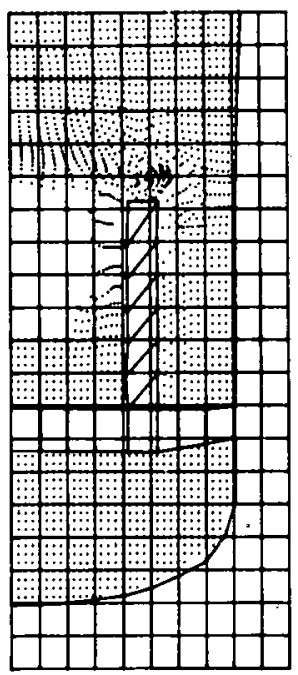

$t=20.3 \mathrm{~ms}$
Fig. 32

Configurations of Primary Containment and Components at Three Different Times. ANL Neg. No. 900-77-712.
Fig. 33

Calculated Axial Displacements as a Function of Time. ANL Neg. No. 900-77-341.

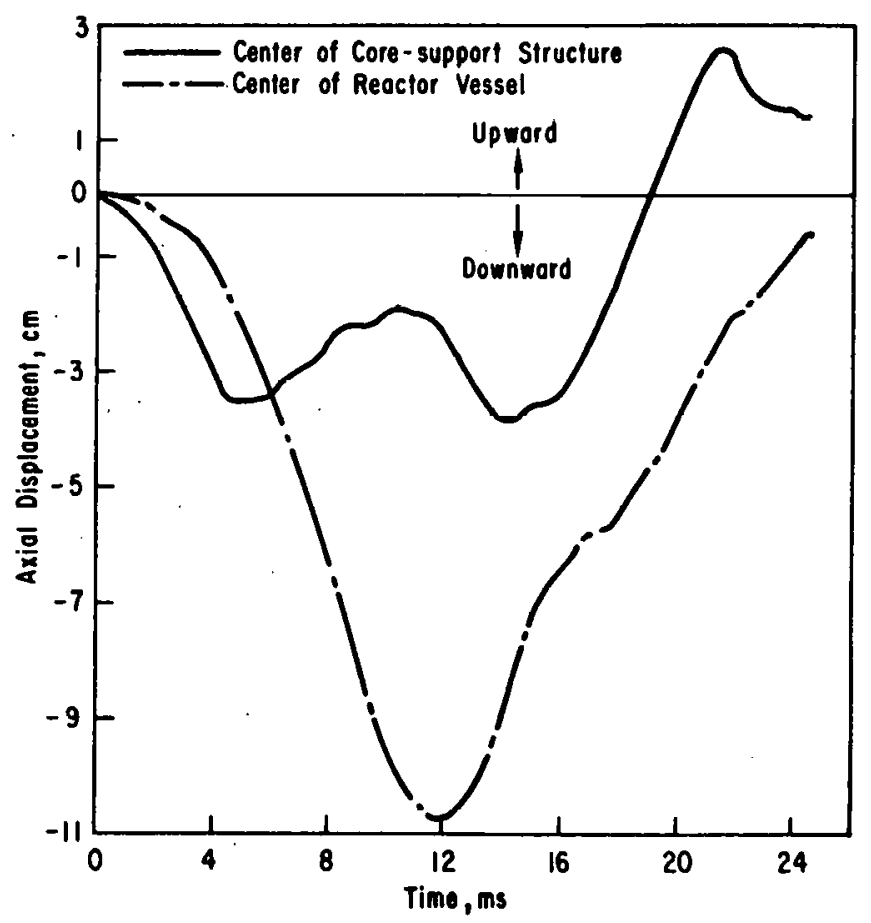


The radial displacements of the shield material and core barrel (nodes A and B in Fig. 31) at the core midplane are shown in Fig. 34. Due to the strong outward pressure gradient the peak displacements are found at $6 \mathrm{~ms}$. Thereafter, the pressure between the barrel and the primary vessel gradually builds up and thus causes the displacements to decrease. The peak displacement of the shield material is greater than that of the core barrel. This is because the radial shield is treated as compressible fluid which has less rigidity than the core barrel.

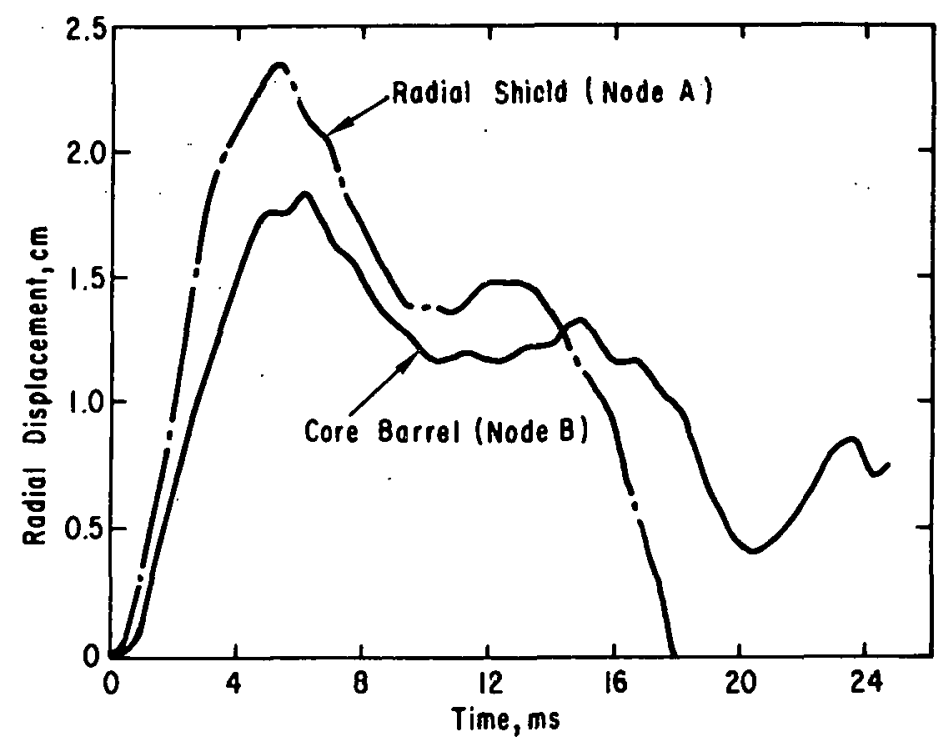

Fig. 34

Calculated Radial Displacements as a Function of Time. ANL Neg. No. 900-77-340. 


\section{CONCLUSIONS}

A generalized coupling scheme has been incorporated into the second version of ICECO (ICECO-STR) which links together the Eulerian hydrodynamics and Lagrangian structural-mechanics programs for the fluid-structure interaction analysis in nuclear reactors subjected to an HCDA. The physical phenomena considered by the technique and the resulting program, ICECO-STR, include the wave propagation, sodium-slug impact, coolant spillage, gas-bubble migration, as well as the structural response. The numerical algorithm has many special features:

(1) It employs the implicit temporal integration scheme in both the hydrodynamics and fluid-structure interaction analyses. The solution is unconditionally stable. We have found that except in the problem involving shock discontinuities, the effects of viscosities on the numerical results are insignificant.

(2) It uses the Eulerian coordinate system in treating the fluid motion in which the material may undergo large distortion. Hence, no mesh stabilization, mesh regularization, or rezoning are needed in the analysis.

(3) The technique treats complex boundary conditions at the fluidstructure interface and yet still maintains the computational efficiency. The computing time for problems involving a typical reactor configuration is found to be comparable to the conventional Lagrangian technique.

(4) The hydrodynamic analysis can be readily coupled with any structural-dynamic program whenever a more advanced one becomes available. The presently used structural program is based on a well-developed finite-element method which can account for both material and geometrical nonlinearities.

(5) It has capabilities of treating sodium flow through the openings of the core-support structure as well as through the penetration openings of the reactor cover and the ruptured seal at the vessel-cover junction. This is not only important to the integrity of the primary containment, but also essential to the analysis of transport of radiological material to the secondary containment.

In developing the ICECO code, one ultimate objective is to assist the REXCO code in the safety analys is of LMFBRs, particularly in excursions involving large material distortions. It is believed that this objective is $s$ at isfactorily achieved. Thus, these two codes can be used in conjunction with each other, with REXCO being more appropriate for the early stage of an excursion to determine the wave propagation and structural response, and ICECO being more adequate for the later stages to investigate the bubble motion and coolant spillage. In fact, such REXCO-ICECO combination analysis has been successively applied to the double-vessel reactor configuration of the SNR-300 Experiment. ${ }^{20}$ 
As demonstrated by the results of the sample problems, the ICECO is capable of analyzing two dimensionally the fluid-structure interaction and the resulting containment response during an HCDA. The code provides numerous options for modeling the complicated structure components, including the rigid obstacles, rigid thin membranes, curved reactor vessel, deformable internals, and perforated core-support structure, as well as the movable head with penetrations. The basic coupling scheme has been validated by comparing the code solution with the REXCO-code prediction and experimental data of SNR - 300 breeder reactor. The good agreement obtained in this comparison further lends credibility that ICECO can be used for analyzing the fluid transient and the fluid-structure interaction.

The coolant flows through penetration openings on the vessel head and the perforated openings of the core-support structure are two options recently incorporated into the program. These two options have not yet been subjected to rigorous test against the experimental data. However, the analys is is to be compared with the available test results in the near future so that any needed improvement can be immediately made.

The ICECO code has wide range of applicability. In a forthcoming report ${ }^{21}$ numerous sample problems will be given, together with input instruction to the computer program. These examples reflect the studies of (1) bubble expansion and migration, (2) wave transients in the piping components, (3) response of the primary containment, (4) the effect of openings of the coresupport. structure on the wave propagations, (5) sodium spillage through penetration openings on the reactor cover, and (6) heat transfer.

Future development worlc should concentrate in two key areas: bubble migration and interaction of fluid with the upper core structure. The inclusion of bubble inertia is necessary since it could have significant effects in the later stage of bubble motion and in the bubble interaction with the surrounding coolant and structure. The upper core structure also should be included in the numerical analysis so that the containment response can be accurately predicted. Also, the code should be further extended to treat the deformable inner vessel. This is of great importance to model exactly the skirt connecting the core-support structure and the primary vessel, as well as to study the interaction of fluid with internal baffle plates in the piping components, such as valve and heat exchanger. Thus, with the ongoing effort of extending the code versatility, the ICECO promises to be a valuable tool in the safety studies of fast breeder reactors. 


\section{APPENDIX \\ Formulation of Explicit Boundary Conditions}

The explicit forms of the inviscid boundary conditions can be formulated by computing the midpoint velocity components at the advanced time through an interpolating formula used in the MAC method. The unknown velocities at the exterior sides of the Eulerian cells and other exterior points are calculated from the mass equation with respect to the boundary cell or simply from the condition of inviscidness. From the difference expressions of the momentum equations one can obtain

$$
\begin{aligned}
& u_{i+(1 / 2), j}^{n+1}=\left[\bar{R}_{i+(1 / 2), j}+\frac{\delta t}{\delta r}\left(p_{i, j}^{n+1}-p_{i+1, j}^{n+1}\right) \varphi\right] / \rho_{i+(1 / 2), j}^{n+1}, \\
& u_{i-(1 / 2), j}^{n+1}=\left[\bar{R}_{i-(1 / 2), j}+\frac{\delta t}{\delta r}\left(p_{i-1, j}^{n+1}-p_{i, j}^{n+1}\right) \varphi\right] / \rho_{i-(1 / 2), j}^{n+1}, \\
& v_{i, j+(1 / 2)}^{n+1}=\left[\bar{S}_{i, j+(1 / 2)}+\frac{\delta t}{\delta z}\left(p_{i, j}^{n+1}-p_{i, j+1}^{n+1}\right) \varphi\right] / \rho_{i, j+(1 / 2)}^{n+1},
\end{aligned}
$$

and

$$
v_{i, j-(1 / 2)}^{n+1}=\left[\bar{S}_{i, j-(1 / 2)}+\frac{\delta t}{\delta z}\left(p_{i, j-1}^{n+1}-p_{i, j}^{n+1}\right) \varphi\right] / \rho_{i, j-(1 / 2)}^{n+1},
$$

where

$$
\begin{aligned}
& \bar{R}_{i+(1 / 2), j}=(\rho u)_{i+(1 / 2), j}^{n}+\delta t\left[\frac{1-\varphi}{\delta r}\left(p_{i, j}^{n}-p_{i+1, j}^{n}\right)+R_{i+(1 / 2)} j\right] \\
& \bar{S}_{i, j+(1 / 2)}=(\rho v)_{i, j-(1 / 2)}^{n}+\delta t\left[\frac{1-\varphi}{\delta z}\left(p_{i, j}^{n}-p_{i, j+1}^{n}\right)+S_{i, j+(1 / 2)}\right]
\end{aligned}
$$

are the modified source terms containing the source term of the momentum equation, densities, velocities, and pressure gradients at the nth cycle. $\bar{R}_{i-(1 / 2), j}$ and $\bar{S}_{i, j-(1 / 2)}$ can be evaluated from $\bar{R}_{i+(1 / 2)}, j$ and $\bar{S}_{i, j+(1 / 2)}$ by replacing indexes $i$ with $i-1$ and $j$ with $j-1$, respectively. $\bar{p}$ is the tentative advanced-time densities which can be approximately evaluated from the values of two previous cycles:

$$
\bar{\rho}_{i, j} \cong \rho_{i, j}^{n}+\left(\rho_{i, j}^{n}-\rho_{i, j}^{n-1}\right)\left(t^{n+1}-t^{n}\right) /\left(t^{n}-t^{n-1}\right)
$$

Thus, for the case of containment vessel with almost vertical orientation shown in Fig. Al, the particle velocity components at the midpoint of the segment are 


$$
u_{p}^{n+1}=\left(\frac{1}{2}+\frac{d}{\delta r}\right) u_{i-(1 / 2), j}^{n+1}+\left(\frac{1}{2}-\frac{d_{1}}{\delta r}\right) u_{i+(1 / 2), j}^{n+1}
$$

and

$v_{p}^{n+1}=\frac{1}{2}\left(1-\frac{d}{\delta r}\right)\left(v_{i, j+(1 / 2)}^{n+1}+v_{i, j-(1 / 2)}^{n+1}\right)+\frac{1}{2} \frac{d}{\delta r}\left(v_{i-1}^{n+1}, j+(1 / 2)+v_{i-1, j-(1 / 2)}^{n+1}\right)$.

For fluids with small viscosities, the inviscid boundary condition yields

$$
v_{i, j+(1 / 2)}^{n+1}=v_{i-1, j+(1 / 2)}^{n+1} \text { and } v_{i, j-(1 / 2)}^{n+1}=v_{i-1, j-(1 / 2)}^{n+1} \text {. }
$$

From the mass-conservation equation we obtain

$$
\begin{aligned}
u_{i-1(1 / 2), j}^{n+1}= & \frac{r_{i} \delta r}{\theta r_{i+(1 / 2)} \bar{\rho}_{i+(1 / 2), j}}\left\{\frac{\theta}{\bar{\delta} r}(\rho u)_{i-(1 / 2), j}^{n+1} r_{i-(1 / 2)}+\frac{\theta}{\bar{\delta} z}(\rho v)_{i, j-(1 / 2)}^{n+1}\right. \\
& \left.-(\rho v)_{i, j+(1 / 2)}^{n+1}+D_{r}+D_{z}+\rho_{i, j}^{t}\right\},
\end{aligned}
$$

where

$$
\begin{aligned}
& D_{r}=\frac{\theta}{r_{i} \delta r}\left[(\rho u)_{i-(1 / 2), j}^{n} r_{i-(1 / 2)}-(\rho u)_{i+(1 / 2), j}^{n} r_{i+(1 / 2)}\right] \\
& D_{z}=\frac{\theta}{\delta z}\left[(\rho v)_{i, j-(1 / 2)}^{n}-(\rho v)_{i, j+(1 / 2)}^{n}\right] \\
& \rho_{i, j}^{t} \cong\left(\bar{\rho}_{i, j}-\rho_{i, j}^{n}\right) / \delta t
\end{aligned}
$$

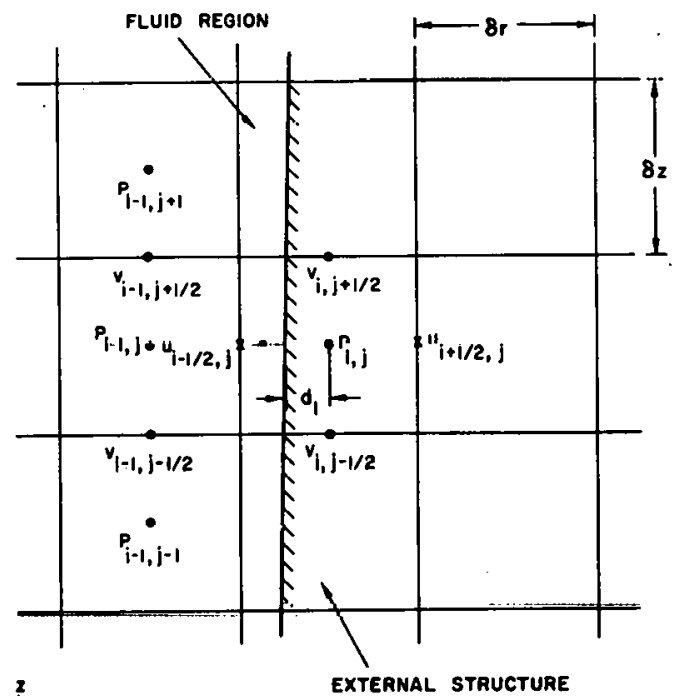

$$
\begin{aligned}
& \text { Fig. A1 }
\end{aligned}
$$


At the fluid-structure interface, the inviscid (free slip) boundary condition yields

$$
\left(\overline{\mathrm{V}}_{\mathrm{p}}^{\mathrm{n}+1}-\overline{\mathrm{V}}_{\mathrm{b}}\right) \cdot \overline{\mathrm{n}}=0
$$

Substitution of exterior velocities expressed in Eqs. A3 and A4 into the interpolating formulas for the midpoint velocities shown in Eq. A2, and in turn using Eqs. Al and A5, yields the explicit condition for the example given in Fig. Al:

$$
\begin{aligned}
m u_{b} & -v_{b}-c_{1}-c_{2} \bar{R}_{i-(1 / 2), j}+c_{3} \bar{S}_{i-1, j+(1 / 2)}+c_{4} \bar{S}_{i-1, j-(1 / 2)} \\
& =\varphi \delta t\left\{-\frac{c_{2}}{\delta r} p_{i, j}^{n+1}+\left(\frac{c_{2}}{\delta r}-\frac{c_{3}-c_{4}}{\delta z}\right) p_{i-1, j}^{n+1}+\frac{c_{3}}{\delta z} p_{i-1, j+1}^{n+1}-\frac{c_{4}}{\delta z} p_{i-1, j-1}^{n+1}\right\},
\end{aligned}
$$

in which

$$
\begin{aligned}
& c_{1}=m\left(\frac{1}{2}-\frac{d}{\delta r}\right) \frac{r_{i} \delta r}{\bar{\rho}_{i+(1 / 2), j} r_{i+(1 / 2)} \theta}\left[D_{r}+D_{z}-\rho_{i, j}^{t}\right] ; \\
& c_{2}=m\left(\frac{1}{2}+\frac{d}{\delta r}\right) \frac{1}{\bar{\rho}_{i-(1 / 2), j}}+\left(\frac{1}{2}-\frac{d}{\delta r}\right) \frac{r_{i-(1 / 2)}}{\bar{\rho}_{i+(1 / 2), j} r_{i+(1 / 2)}} ; \\
& c_{3}=\frac{1}{2 \bar{\rho}_{i-1, j+(1 / 2)}}+m\left(\frac{1}{2}-\frac{d}{\delta r}\right) \frac{r_{i} \delta r}{\bar{\rho}_{i+(1 / 2), j} r_{i+(1 / 2)} \delta z} ; \\
& c_{4}=\frac{1}{2 \bar{\rho}_{i-1, j-(1 / 2)}}-m\left(\frac{1}{2}-\frac{d}{\delta r}\right) \frac{r_{i} \delta r}{\bar{\rho}_{i+(1 / 2), j} r_{i+(1 / 2)} \delta z},
\end{aligned}
$$

Similarly, for the vessel with almost horizontal orientation shown in Fig. A2 we have

$$
\begin{aligned}
& u_{p}^{n+1}=\frac{1}{2} \frac{d}{\delta z}\left(u_{i-(1 / 2), j-1}^{n+1}+u_{i+(1 / 2), j-1}^{n+1}\right)+\frac{1}{2}\left(1-\frac{d}{\delta z}\right)\left(u_{i-(1 / 2), j}^{n+1}+u_{i+(1 / 2), j}^{n+1}\right) ; \\
& v_{p}^{n+1}=\left(\frac{1}{2}+\frac{d}{\delta z}\right) v_{i, j-(1 / 2)}^{n+1}+\left(\frac{1}{2}-\frac{\delta}{\delta z}\right) v_{i, j+(1 / 2)}^{n+1} ;
\end{aligned}
$$

$u_{i+(1 / 2), j-1}^{n+1}=u_{i+(1 / 2), j}^{n+1}$ and $u_{i-(1 / 2), j-1}^{n+1}=u_{i-(1 / 2), j}^{n+1}$ 
The inviscid boundary condition implies

$$
\begin{gathered}
m u_{b}-v_{b}-c_{1}-c_{2} \bar{R}_{i-(1 / 2), j}+c_{3} \bar{R}_{i+(1 / 2), j}+c_{4} \bar{S}_{i, j+(1 / 2)}=\cot t\left\{-\left(\frac{c_{2}+c_{3}}{\delta r}\right.\right. \\
\left.\left.+\frac{c_{4}}{\delta z}\right) p_{i, j}^{n+1}+\frac{c_{2}}{\delta r} p_{i-1, j}^{n+1}+\frac{c_{3}}{\delta r} p_{i+1, j}^{n+1}+\frac{c_{4}}{\delta z} p_{i+1, j}^{n+1}\right\},
\end{gathered}
$$

in which

$$
\begin{aligned}
& c_{1}=\left(\frac{1}{2}+\frac{d}{\delta z}\right) \frac{\delta z}{\theta \bar{p}_{i, j-(1 / 2)}} D_{r}+D_{z}-\rho_{i, j}^{t} ; \\
& c_{2}=\frac{m}{2 \bar{\rho}_{i-(1 / 2), j}}+\left(\frac{1}{2}+\frac{d}{\delta z}\right) \frac{r_{i-(1 / 2)} \delta z}{\bar{\rho}_{i, j-(1 / 2)} r_{i} \delta r} ; \\
& c_{3}=-\frac{m}{2 \bar{\rho}_{i+(1 / 2), j}}+\left(\frac{1}{2}+\frac{d}{\delta z}\right) \frac{r_{i+(1 / 2)} \delta z}{\bar{\rho}_{i, j-(1 / 2)} r_{i} \delta r} ; \\
& c_{4}=\left(\frac{1}{2}+\frac{d}{\delta z}\right) \frac{1}{\bar{\rho}_{i, j-(1 / 2)}}+\left(\frac{1}{2}-\frac{d}{\delta z}\right) \frac{1}{\bar{\rho}_{i, j+(1 / 2)}} .
\end{aligned}
$$

Equations $A 5$ and $A 7$ represent the explicit boundary conditions at the fluidvessel interfaces corresponding to the vessel orientations shown in Figs. Al and $A 2$, respectively. In these equations nonlinear convective flux terms are computed only at the interior sides of the boundary cells. Because of variable cocfficients inulliplying the pressures and the variable number of cells associated with different orientations of the boundary segments, the iteration process is generally slowed. Also, for the reactor containment or a component having a curved boundary there are numerous special cases, so that the derivation of explicit boundary conditions appears to be an insurmountable task.

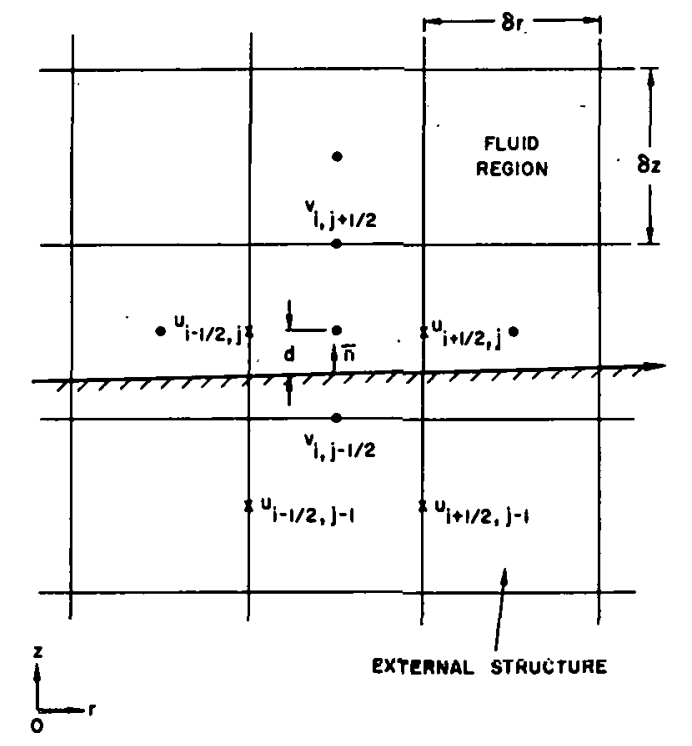

Fig. A2

Vessel with Almost Horizontal Orientation for the Derivation of the Explicit Boundary Condition. ANL Neg. No. 900-78-920. 


\section{ACKNOW LEDGMENTS}

The author likes to express his appreciation to Drs. S. H. Fistedis and $Y$. W. Chang for their constant encouragement and support. Thanks are also due to all the members in the Engineering Mechanics Section who directly or indirectly provided assistance during the course of the code development. 


\section{REFERENCES}

1. S. H. Fistedis, "Containment of Fast Breeder Reactors - Present Status Remaining Problems," First Intl. Conf. on Structural Mechanics in Reactor Technology, Berlin, Germany, September 20-24, 1971.

2. Y. W. Chang and J. Gvildys, REXCO-HEP: A Two-dimensional Computer Code for Calculating the Primary System Response in Fast Reactors, ANL-75-19 (June 1975).

3. M. S. Cowler, N. E. Hoskin, and A. G. Rowlinson, "Calculation of the Dynamic Response of Reactor Containment System to Full-core Explosions," Second Intl. Conf. on Structural Mechanics in Reactor Technology, Berlin, Germany, September 10-14, 1973.

4. F. H. Harlow and A. A. Amsden, A Numerical Fluid Dynomies Caleulation Method for all Filow Speeds, J. Comp. Phys. 8, 197 (1971).

5. F. H. Harlow and A. A. Amsden, Flow of Interpenetrating Material Phase, J. Comp. Phys. 18, 440 (1975).

6. C. Y. Wang, ICECO-An Implicit Eulerian. Method for Calculating Fluid Transients in Fast-Reaclor Containment, ANL-75-81 (Dec 1975).

7. S. Hancock, Finite Difference Equations for PISCES/2DELK, Physics International Company Report TCAM 76-2 (1976).

8. W. F. Noh, "CEL: A Time-Dependent, Two Space-Dimensional Coupled Eulerian Lagrangian Code," Methods in Computational Physics, Vol. 3, B. Alder, S. Fernbach and M: Rotenberg, eds., Academic Press Inc., N.Y. (1964).

9. J. E. Welch et al., The MAC Method, A Computing Technique for Solving Viscous, Incompressible, Transient Fluid Flow Problems Involving Free Surfaces, LA-3425 (March 1966).

10. C. W. Hirt, Heuristic Stability Theory for Finite Difference Equations, J. Comp. Phys. 2, 339 (1968).

11. J. A. Viecelli, A Method for Including Axbitrary External Boundaries in the MAC Incompressible Fluid Computing Technique, J. Comp. Phys. 4, 543-551 (1969).

12. J. A, Vieccelli, A Computing Method for Incompressible Flows Bounded by Arbitrary Walls, J. Comp. Phys. 8, 119-143 (1971).

13. H. Schlichting, Boundary-Layer Theory, McGraw-Hill Book Co., Inc., New York, N.Y. (1969).

14. H. Y. Chu, C. Y. Wang, J. Gvildys, and Y. W. Chang, "A Generalized Eulerian Method in Reactor Containment Analysis and its Comparison with other Numerical Methods," Proc. of the Inth. Meeting on Fast Reactor Safety and Related Physics, CONF-761001, Vo1. III, p. 1285, Chicago, Illinois, October 5-8, 1976.

15. T. Belytschko and B. J. Hsieh, Nonlinear Transient Analysis of Shells and Solids of Revolution by Convected Elements, AIAA J. 12, No. 8, 1031 (1974).

16. T. Belytschko, WHAMS-Waves in Hysteretic Arbitrary Media and Structures, Dept. of Material Engineering, University of Illinois at Ch1cago Circle (1974). 
17. A. H. Marchertas, Analysis of a Thin Axisymmetric Shell Subjected to Dynamic Loading and Large Deformation, Argonne National Laboratory Intralaboratory memo to S. H. Fistedis, RAS, January 1973.

18. E. A. Witmer et al., Large Dynomic Deformations of Beams, Rings, Plates, and Shells, AIAA J. 1, No. 8, 1848 (1963).

19. M. Stievenart et a1., Analysis of LMFBR Explosion Model Experiments by Means of the S4BROUM-II Code, Paper E 3/5, 3rd IntZ. Conf. on Structural Mechanics in Reactor Technology, London, September 1-5, 1975.

20. A. H. Marchertas, C. Y. Wang, and S. H. Fistedis, "Simulation of LMFBR Excursion Models by Means of ICECO," 4th Intl. Conf. on Structural Mechanics in Reactor Technology, San Francisco, California, August 15-19, 1977, paper E $2 / 5$.

21. C. Y. Wang et al., ICECO Analysis of Primary System Response to an HCDA, Argonne National Laboratory Report, in preparation. 
Internal:
J. A. Kyger
R. H. Sevy
J. M. Kennedy
L. Burris
W. C. Lipinski
R. F. Kulak
D. W. Cissel
D. H. Cho
A. H. Marchertas
S. A. Davis
L. W. Deitrich
B. R. T. Frost
S. H. Fistedis
R. J. Teunis
D. R. Ferguson
C. E. Till
D. Myers (5)
R. S. Zeno
R. A. Noland
M. T. Abdel-Moneim
H. J. Petroski
H. L. Schreyer
C. Y. Wang (33)
H. O. Monson
C. E. Dickerman
W. Z euch
R. Avery
A. E. Klickman
A. B. Rothman
J. F. Marchaterre
J. B. Heineman
A. DeVolpi
A. J. Goldman
J. E. Ash
R. E. Henry
H. K. Fauske
Y. W. Chang
D. H. Lennox
I. Bornstein
H. Y. Chu
B. A. Korelc (3)
C. Fiala
T. C. Chawla
J. L. Glazik
L. Baker
J. Gvildys
J. H. Tessier
D. R. Pedersen
A. B. Krisciunas
ANL Contract File ANL Libraries (5)
P. A. Lottes TIS Files (6)

\section{External:}

DOE-TIC, for distribution per UC-79p (276)

Manager, Chicago Operations Office

Chief, Office of Patent Counsel, CH

Diroctor, Reastor Prngrams, $\mathrm{CH}$

Director, CH-INEL

Director, DOE-RRT (2)

President, Argonne Universities Association

Reactor Analysis and Safety Division Review Committee:

E. Baron, Burno and Roo, Inc.

J. R. Dietrich, Combustion Engineering, Inc.

W. Kerr, U. Michigan

M. Levenson, Electric Power Research Inst.

S. Levy, S. Levy, Inc.

D. Okrent, U. California, Los Angeles

N. C. Rasmussen, Massachusetts Inst. Technology 